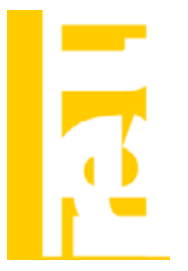

\title{
LA BRECHA DE INGRESOS POR GÉNERO EN ARGENTINA: DESCOMPOSICIÓN DE LA DISCRIMINACIÓN CONTRA TRABAJADORES INDEPENDIENTES Y TRABAJADORES ASALARIADOS
}

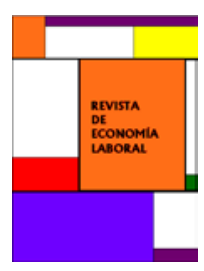

\author{
Juan Pablo Carranza*1 y María Verónica Alderete** \\ * Universidad Siglo 21 \\ ** IEES-CONICET, Universidad Nacional del Sur
}

Recibido 25 Marzo 2014; aceptado 4 Julio 2014

\section{Resumen}

El objetivo de este trabajo es estimar la brecha de ingresos por género entre trabajadores de Argentina, y su relación con la segregación y discriminación laboral. El método de descomposición de Oaxaca-Blinder, ajustado por sesgo de selección muestral, arroja una brecha en el logaritmo del ingreso horario de 0,029 favorable a los varones. Las mujeres tienen una mayor dotación de capital humano, pero la retribución que obtienen del mismo es menor que para los varones. La segregación vertical reduce sólo el ingreso de las mujeres y la feminización de sectores económicos implica un costo para ambos sexos. Cuando el modelo se circunscribe al caso de los trabajadores asalariados, aumentan tanto la brecha de ingreso por género como la participación de los retornos al capital humano.

Palabras clave: Discriminación por género, Mercado laboral, Diferencial de ingresos.

Clasificación JEL: J71, J31.

\begin{abstract}
The objective of this paper is determining the gender income gap among workers from Argentina, and its relationship with occupational segregation and discrimination. The Oaxaca-Blinder decomposition adjusted for self-selection offers a natural log of hourly income gap of 0.029 that favors men. Results show that women are endowed with larger human capital stock than men, and their reward is relatively lower. Vertical segregation reduces only women income. Besides, the feminization of economic sectors is costly both for men and women. When analyzing the case of wage-earners, the gender income gap increases as well as the participation of the coefficients component.
\end{abstract}

Key words: Gender discrimination, Labour market, Income gap.

JEL Classification: J71, J31.

1 Correspondencia: Juan Pablo Carranza, juan.carranza@ues21.edu.ar; María Verónica Alderete, mvalderete@iiess-conicet.gob.ar.

(C) Revista de Economía Laboral 


\section{Introducción}

La determinación de los salarios ha sido tema de abundante análisis en el área de economía laboral. La línea de investigación más popular se basa en la teoría del Capital Humano (Becker, Human Capital: A Theoretical and Empirical Analysis, with Special Reference to Education, 1975) que, en el marco del equilibrio neoclásico para el mercado laboral en donde los salarios de las personas son determinados sólo por su productividad, supone que las diferentes cantidades de capital humano acumuladas por los individuos impactan en sus remuneraciones. En este sentido, un trabajador con mayor cantidad de capital humano acumulado será más productivo, y debería percibir un mayor salario. Posteriormente, con el avance de la Economía de la Información, se planteó que el capital humano impacta en los salarios de las personas como un mecanismo de señalización que aproxima la productividad. En base a lo anterior, el capital humano cumple un rol fundamental en la determinación de los salarios (Mincer, 1974). Sin embargo, esta teoría no explica de manera satisfactoria las diferencias frecuentemente observadas en las remuneraciones de personas, o grupos de personas, con similares dotaciones de capital humano, en donde la única diferencia visible es su raza, género o edad.

La presencia de brechas de ingreso entre diferentes grupos de personas para empleos con similares características se ha convertido en una preocupación creciente a nivel mundial. Este interés se evidencia en la literatura reciente para los países en desarrollo (Esparta Polanco, 2012; Barraza Narváez, 2010; Atal et al, 2009; Esquivel, 2007; Fuentes et al, 2005; Flores y Jasso, 2004; Zúñiga y Orlando, 2001; Paz, 2000). La discriminación de ingresos en contra de las mujeres es particularmente alarmante ya que podría constituirse en un factor clave que limite la participación de la mujer en la fuerza de trabajo y el logro de progresos económicos y sociales.

Esta investigación se propone analizar las diferencias de ingreso por género, contemplando a la totalidad de los trabajadores argentinos, tanto asalariados como no asalariados (trabajadores por cuenta propia y empleadores). Si bien la proporción de trabajadores por cuenta propia es de una magnitud inferior a la de los trabajadores asalariados, su participación en la estructura ocupacional argentina es relativamente importante, sobre todo en comparación con los países más desarrollados (Ministerio de Trabajo, Empleo y Seguridad Social de la República Argentina, 2006). La evolución de las categorías ocupacionales no asalariadas muestra una reducción de su participación relativa de $27 \%$ a $24 \%$ de la Población 
Económicamente Activa (PEA) ocupada entre 2003 y 2011 (Palomino \& Dalle, 2012).

El principal rasgo discriminatorio que se observa en el mercado de trabajo argentino consiste tanto en las diferencias en los ingresos de varones y mujeres que realizan trabajos similares, como en la segregación ocupacional por género, ya sea en el acceso a empleos de diversa calidad (segregación vertical) o entre diversos tipos de actividad económica (segregación horizontal).

Es importante estimar la magnitud de la brecha de ingresos, así como identificar los determinantes de los ingresos para cada grupo para clarificar el rol que cumplen distintos factores socio-económicos en la determinación de los ingresos de cada género, con el objetivo de acompañar el diseño de políticas públicas que busquen regular esta problemática. A estos fines, se utiliza el método de descomposición de Oaxaca-Blinder para estimar la brecha de ingresos explicada por discriminación, se corrige la estimación por sesgos de selección en la muestra, y se incorporan variables que captan la segregación ocupacional por género.

\section{Marco teórico}

Becker (1971) y Altonji y Blank (1999) consideran a la discriminación salarial y la segregación ocupacional como fenómenos relacionados con la demanda de trabajo. La discriminación en el mercado laboral es una situación en la que dos personas (o grupos de personas), igualmente productivas en el sentido material y físico, son tratadas de manera diferente (una de ellas, peor) sólo en virtud de características observables, como su género. Esto se deriva tanto en niveles de ingreso diferentes para individuos comparables (discriminación de ingresos) como en diferentes demandas de sus servicios de trabajo al ingreso vigente (segregación ocupacional).

Cabe señalarse que la discriminación, como concepto, puede surgir por diferentes razones, ya sea por el origen social, racial, étnico u otra característica que permita caracterizar grupos de personas. Sin embargo, el fenómeno que ha recibido mayor atención en Argentina, y en varios países del mundo, es el de discriminación por género.

Los estudios empíricos que analizan los determinantes de la brecha salarial por género en Argentina se focalizan en la Teoría del Capital Humano (diferencias en dotaciones) y en la discriminación salarial (diferencias en retornos por dotaciones).

Esquivel (2007) realiza un análisis de los efectos de la discriminación en los salarios de varones y mujeres, utilizando datos de la 
Encuesta Permanente de Hogares continua $(\mathrm{EPH})^{2}$ para los años 2003 y 2006. Para tal fin, analiza el efecto de la inserción diferencial por género en puestos regulares o de calidad (estables, formales y sin subocupación horaria involuntaria) en el diferencial salarial, a través de la metodología propuesta por Neuman y Oaxaca (2004). La autora observa que la brecha salarial para los puestos regulares es sorprendentemente favorable a las mujeres. En cuanto a la segregación ocupacional, Esquivel (2007) encuentra que las mujeres y varones que trabajan en ocupaciones más feminizadas obtienen un premio salarial, y el mismo es mayor aún en el caso de las mujeres.

Paz (2000) encuentra que la brecha de ingresos mensuales entre mujeres y varones ronda el 30\%; esto es, los ingresos medios femeninos representan alrededor de un $70 \%$ de los masculinos. Sin embargo, cuando las estimaciones se corrigen por selección muestral, y se calcula el ingreso horario en lugar del ingreso mensual, la brecha salarial se invierte. Según Paz (2000) el ingreso horario promedio de las asalariadas es en Argentina un 3.8\% superior que el de los asalariados. Cain (1986) presenta un buen resumen de distintos resultados en materia de discriminación obtenidos para EEUU. Allí puede observarse claramente que cuando el ingreso se mide a partir del salario horario, la discriminación en contra de las mujeres varía en un rango que va del 15\% al 40\% dependiendo de la forma de medir productividad y del año analizado.

Asimismo, existe una serie de estudios sobre las brechas salariales en varios países de América Latina. Atal, Nopo y Winder (2009) sintetizan los resultados obtenidos en toda la región. Este estudio realiza una investigación empírica integral sobre las diferencias salariales, compara salarios entre individuos con las mismas características demográficas y aquellas que están vinculadas al trabajo, como la edad, el nivel de educación, el lugar de residencia y el tipo de empleo, entre otros indicadores. Los economistas dividieron el análisis de las brechas de salario

2 Según el Instituto Nacional de Estadísticas y Censos, la Encuesta Permanente de Hogares (EPH) es un programa de investigación de la realidad social del país. Se nutre de información a través de una encuesta que permite conocer las características demográficas y socioeconómicas de la población, vinculadas a la fuerza de trabajo. El programa alcanza a todo el territorio nacional y, si bien abarca numerosas problemáticas propias de la Argentina, cumple con estándares internacionales para ser utilizada en estudios comparativos regionales. La obtención de datos se realiza mediante encuestas trimestrales a, aproximadamente, 25.000 hogares que van rotando cada dos trimestres. Para mayor información sobre los aspectos metodológicos de la encuesta se sugiere acceder a: http://www.indec.gov.ar/nuevaweb/cuadros/4/Metodologia_EPHContinua.pdf 
en dos partes. Por un lado, se interrogaron hasta qué punto los trabajadores con las mismas características ganan diferentes salarios sobre la base de su género o etnicidad. Y por otro lado, exploraron hasta qué punto las mujeres y las minorías étnicas carecen de acceso a ciertas combinaciones de características que podrían permitirles obtener mejores retribuciones en sus respectivos mercados laborales. Psacharopoulos y Tzannatos (1991) también concluyen que el grado de discriminación por género es importante en los países de la región, y que el grado de sesgo de selección es alto como consecuencia de la presencia de una participación de la fuerza de trabajo femenina relativamente baja.

Un hecho que debe considerarse es la segregación ocupacional por género tanto entre sectores (segregación horizontal) como entre puestos jerárquicos u ocupaciones (segregación vertical). Carranza y Peralta (2012) realizan un estudio sobre más de 10.000 solicitudes de empleo por parte de empleadores de la Ciudad de Córdoba (Argentina), observando la escasa posibilidad que tienen las mujeres de acceder a puestos ligados a la toma de decisiones. Las mujeres tienden a estar sobre-representadas en ocupaciones con bajo status, a menudo reciben un trato desigual o son colocadas en ocupaciones estereotipadas, y vulnerables a la discriminación y la explotación sexual (OIT, 2011).

La sobre-representación de mujeres en algunas pocas ocupaciones, como resultado de la discriminación de empleadores y clientes, deprime los ingresos de los trabajadores en estas ocupaciones a causa del exceso de oferta, teoría de crowding o hipótesis de concentración (Bergmann, 1974). Sin embargo, esta hipótesis no explica cómo y por qué las mujeres son relativamente excluidas de puestos de mayor jerarquía (y por lo tanto de mayor calidad y salarios relativos), incluso al interior de sectores más feminizados (Esquivel, 2007). Además, la sobre-representación ocupacional puede surgir aún en ausencia de discriminación, ya sea por diferencias en características laborales no remunerativas entre ocupaciones preferidas por cierto grupo de trabajadores o por elección propia (Macpherson y Hirsch, 1995; Neuman y Oaxaca, 2004).

Goldin (2002) desarrolla un modelo de segregación ocupacional que puede aplicarse tanto a la segregación horizontal como vertical. Supone que los varones, con el fin de mantener el prestigio o status de su ocupación, accionarán para impedir la entrada de mujeres. Se trata de un modelo que pretende sintetizar el enfoque de la discriminación estadística (Aigner y Cain, 1977) con el enfoque del gusto por la discriminación de Becker (Becker, 1957). En un contexto de información imperfecta, en donde las mujeres se incorporan con posterioridad a los varones al mercado laboral, se supone conocida la distribución en los varones de una determinada 
característica necesaria para acceder a empleos de distintos niveles de prestigio, en tanto sólo se conoce el valor de esta característica para la mediana de la distribución de las mujeres. Bajo estos supuestos, más algunas consideraciones de información imperfecta sobre el cambio tecnológico, la entrada de las mujeres a una determinada ocupación puede ser vista por los varones como "contaminante", independientemente de que la mujer cumpla con todos los requisitos necesarios, dado que la sociedad ignora sus características personales y las mismas se juzgan según la mediana del grupo al que pertenece. Cuando se abandonan los supuestos de precios exógenos y rendimientos constantes a escala, la incorporación de mujeres a determinadas ocupaciones afectará la oferta relativa de trabajo en las mismas, generando diferenciales de ingresos.

Macpherson y Hirsch (1995) incorporan a la metodología de OaxacaBlinder una variable que refleja el porcentaje de mujeres en la ocupación, con el objetivo de captar la penalidad salarial asociada a realizar "trabajos de mujeres". Sus resultados muestran que los empleos con elevadas tasas de participación femenina pagan menores salarios tanto a varones como a mujeres. Según los autores, los salarios descienden a medida que aumenta la proporción de mujeres en una ocupación dado que estas actividades predominantemente femeninas implican una menor inducción $\mathrm{y}$ entrenamiento para desempeñarse de una manera eficiente. Por lo tanto, éstas ocupaciones tienden a mostrar una mayor concentración de trabajadores part-time y una mayor rotación de personal (Macpherson y Hirsch, 1995). Dado que no está claro hasta qué punto la decisión de trabajar una menor cantidad de horas corresponde a la mujer o es una imposición del empleador, y tampoco se conoce si la preferencia por empleos con una mayor rotación es propia al género femenino o si se trata de una consecuencia de las (pobres) características del empleo demandado, resulta conveniente analizar la brecha de ingresos en el salario por hora e incluir una mayor cantidad de variables en la ecuación de salarios a los fines de captar una mayor parte de la problemática.

Fortin (2005) realiza un estudio sobre el impacto de la actitud respecto al rol de cada género y los valores del mundo del trabajo sobre el desempeño de la mujer en el mercado laboral, buscando distinguir en qué medida las diferencias de género observadas descansan en la existencia de discriminación y en qué medida reflejan las propias actitudes y preferencias del género femenino. Encuentra que los prejuicios antiigualitarios presentan una correlación negativa más fuerte con las tasas de empleo femeninas y el diferencial de ingresos. Sin embargo, estos prejuicios parecen estar suavizándose en las cohortes más recientes, a pesar de que la percepción del rol de la mujer y su responsabilidad sobre las tareas del 
hogar (ligado a ideologías religiosas) es más persistente a lo largo del tiempo.

\section{Discriminación por género y trabajadores no asalariados}

La consideración de las diferencias de ingresos entre varones y mujeres va en consonancia con una serie de trabajos que analizan la discriminación de ingresos por género tanto para trabajadores asalariados como no asalariados ${ }^{3}$ (Esparta Polanco 2012; Paz, 2005; Carrasco 2004; Flores y Jasso, 2004; Cain 1986).

De acuerdo a la Clasificación Internacional de la Situación de Empleo (CISE-93) se define como trabajadores independientes aquellos cuya remuneración depende directamente de los beneficios, o del potencial para realizar beneficios derivados de los bienes y servicios producidos por la empresa. Entre ellos, se considera trabajadores por cuenta propia a aquellos que trabajando por su cuenta o con algún socio tienen un trabajo independiente y no han contratado a ningún trabajador para trabajar con ellos durante el período de referencia ${ }^{4}$.

Existen algunas particularidades en la legislación argentina que prácticamente obligan a considerar a los trabajadores por cuenta propia a la par de los asalariados a la hora de analizar las diferencias en las remuneraciones por género, independientemente de que en teoría la fijación de ambas remuneraciones no respondan a las mismas reglas de mercado. En el año 1998 se creó una forma de inscripción con fines tributarios (aún vigente) denominada "monotributo", en donde las personas físicas y jurídicas cuyos ingresos no superasen una determinada cantidad de dinero anual realizan un único pago fijo por mes (cuya magnitud varía según el monto de ventas que declare) abarcando el pago del impuesto al valor agregado, impuesto a las ganancias, aporte jubilatorio y obra social. Con el tiempo esta modalidad de inscripción impositiva se convirtió en una importante fuente de informalidad laboral, dado que muchos empleadores adoptaron la práctica de contratar a sus empleados como "proveedores de

\footnotetext{
${ }^{3}$ Aquellos trabajos que excluyen a los trabajadores no asalariados (independientes) se basan en la primera de las tres fuentes de discriminación que menciona Becker (1957): la discriminación por parte de los empleadores.

4 Según la CISE_93 los trabajadores independientes se clasifican en: empleadores, trabajadores por cuenta propia (también llamados trabajadores autónomos para la Seguridad Social), miembros de cooperativas de productores y trabajadores familiares auxiliares.
} 
servicios" adheridos a este régimen, en muchos casos haciéndose cargo del monotributo, dado que el pago del mismo era significativamente menor que los aportes que debía afrontar en caso de formalizar la relación laboral.

Carrasco (2004) considera la situación laboral como trabajador asalariado o por cuenta propia en el modelo, y otorga evidencia para el caso boliviano acerca de una posible relación negativa entre la condición del trabajador cuenta propia y los ingresos laborales. Estas predicciones serían contrarias a las de Lazear y Moore (Lazear y Moore, 1984) ya que en el caso boliviano, como en el argentino, la condición de trabajar por cuenta propia no siempre es una opción. Narváez (2010) utiliza como variable dependiente el logaritmo natural del ingreso laboral de los individuos asalariados y no asalariados sin hacer distinción entre su procedencia. Según Paz (2005), la disparidad de remuneraciones entre sexos asciende en Argentina al $14 \%$ para el conjunto de trabajadores y al $13 \%$ para los asalariados. El autor considera los ingresos de asalariados y trabajadores por cuenta propia.

A su vez, la consideración de la discriminación más allá de la presencia de empleadores discriminadores sigue la concepción de la economía feminista. Esta perspectiva contrasta con la conceptualización de que la discriminación y la segregación ocupacional por razones de género en términos económicos requieren, para su formulación, de la presencia de empleadores discriminadores, una figura inexistente en inserciones laborales no asalariadas.

Bajo esta perspectiva, la desvalorización de las mujeres no proviene exclusivamente de los empleadores discriminadores. No se desvaloriza necesariamente al género femenino. Lo que se desvaloriza son más bien aquellos aspectos de la vida, aquellos atributos, acciones o actitudes, típicamente categorizados como "femeninos" y/o asociados con el costado femenino de la vida humana, ya sea que los mismos sean ejercidos por mujeres o varones. Evidentemente lo que ocurre es que, en un gran porcentaje, dichas tareas y actitudes son realizadas/asumidas en la práctica mayoritariamente por mujeres. Esta idea de la devaluación de las actividades feminizadas ha sido abordada por Eugenia Perona (Perona, 2012) para el sector de educación superior. En consecuencia, es la concepción de desvalorización general de las actividades "feminizadas" lo que conduce a las diferencias de ingresos, incluso cuando las actividades laborales sean no asalariadas (como en caso de los autónomos o cuentapropistas). Se sostiene en éste enfoque que la discriminación es una cuestión social que excede a una figura idealizada de empleador, y que la feminización de actividades, la segregación ocupacional y discriminación 
en los ingresos están presentes en numerosas actividades, más allá de la forma en que idealmente se determinen los salarios.

\section{Marco descriptivo}

Si bien la participación de las mujeres en el mercado laboral $(42,26 \%)$ es menor en relación a los varones (57,74\%), la participación en el ingreso proveniente de la ocupación principal es aún menor para éstas, siendo de $35,41 \%$, frente a un $64,59 \%$ correspondiente a los varones. Es decir, como puede apreciarse en el Gráfico 1, las mujeres participan menos que los varones en el mercado laboral, y su participación en el ingreso es aún menor.

Esta situación se explica, en parte, por el hecho de que las mujeres que participan en el mercado laboral trabajan menos horas en relación a los varones. El promedio de horas trabajadas por semana es de 34,34 para las mujeres y 45,2 para los varones. De allí que el ingreso total mensual tienda a ser menor en las mujeres que en los varones.

En el Gráfico 3 se analiza la condición de actividad de cada género. Se observa que los trabajadores asalariados (obreros o empleados) representan un porcentaje amplio de la muestra, seguido por los cuentapropistas y los patrones. En esta estructura ocupacional las mujeres poseen una mayor participación relativa a los varones entre los asalariados que entre los trabajadores no asalariados. El porcentaje de mujeres asalariadas es de un $82,15 \%$ del total de mujeres que participan en el mercado laboral, mientras que los varones asalariados representan un $74,09 \%$ del total.

En cuanto al nivel educativo por género, se observa una mayor concentración de mujeres en los niveles de instrucción más altos. El porcentaje de mujeres con educación superior finalizada es de $14,73 \%$, mientras que los varones con esa instrucción representan un 9,79\% del total. Así mismo, las mujeres con educación superior incompleta o en curso es de $13,76 \%$, y en los varones este porcentaje es del $12,12 \%$. La elevada proporción de mujeres con instrucción y su escasa participación en el mercado laboral (en relación a los varones) implica costos de oportunidad a la sociedad en términos de mano de obra calificada que permanece improductiva (Carranza y Peralta, 2012). 


\section{Gráfico 1. Participación en el mercado laboral y en el ingreso, según sexo.}

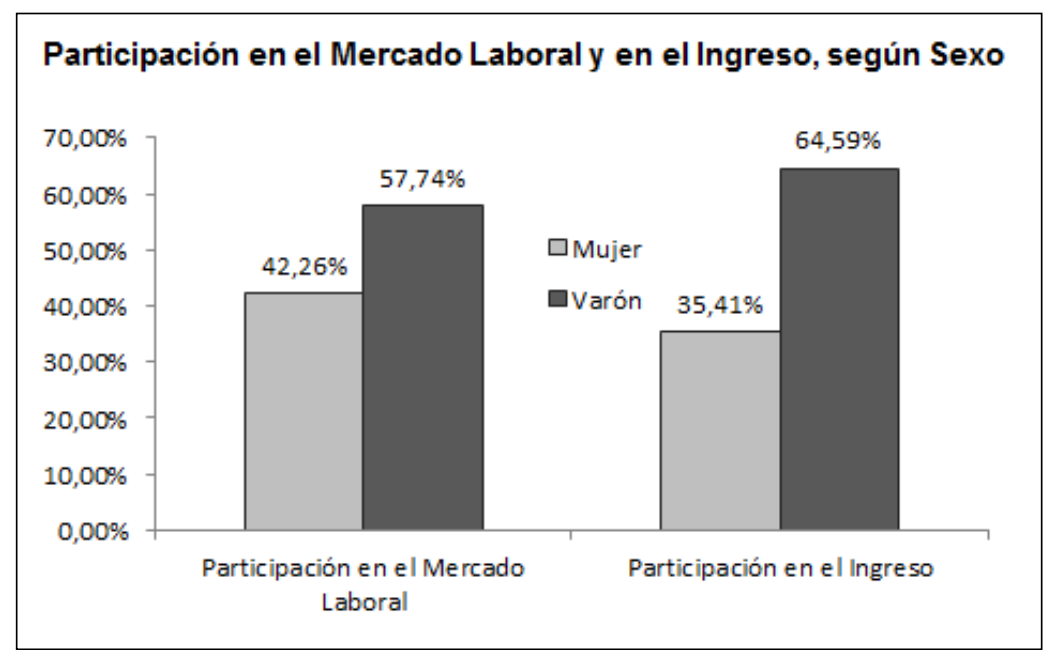

Fuente: Elaboración propia con datos de la EPH para el segundo trimestre de 2012.

Gráfico 2. Condición de actividad, según Sexo.

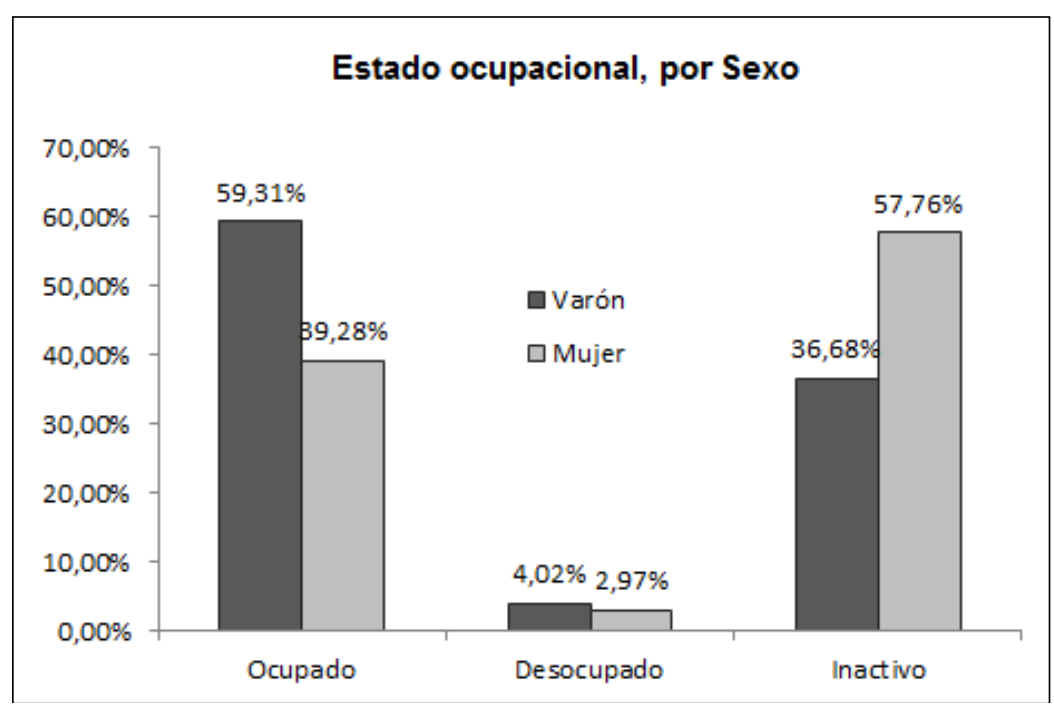

Fuente: Elaboración propia con datos de la EPH para el segundo trimestre de 2012. 


\section{Gráfico 3. Categoría Ocupacional por Sexo.}

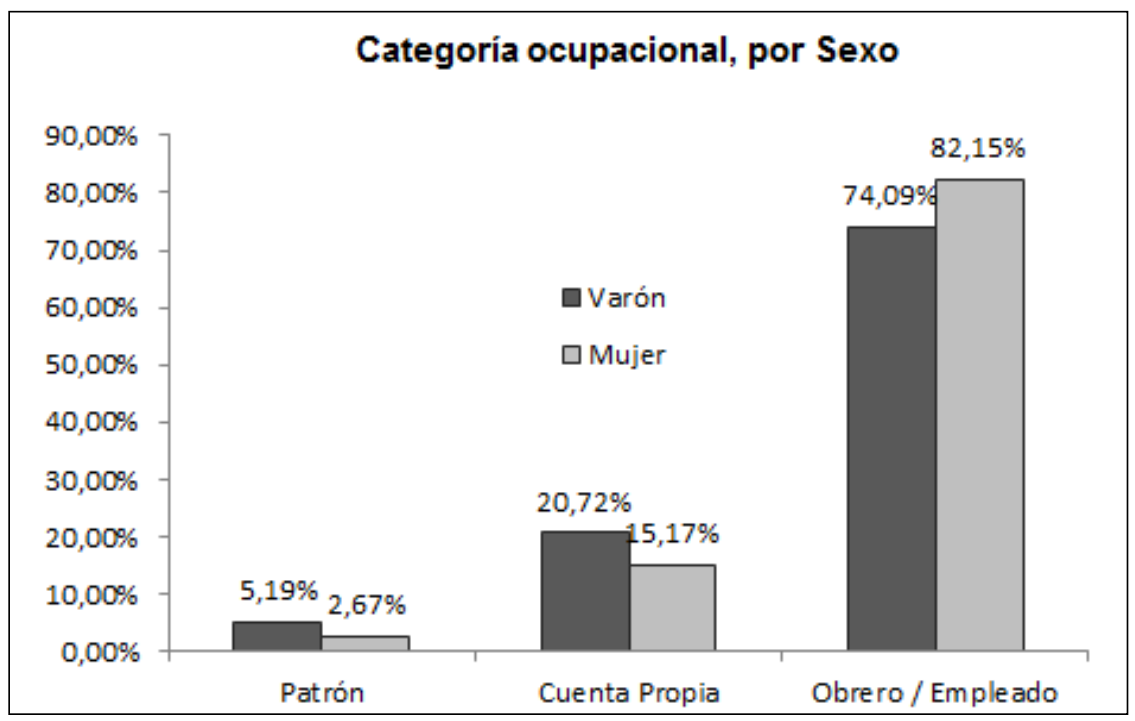

Fuente: Elaboración propia con datos de la EPH para el segundo trimestre de 2012.

\section{Gráfico 4. Nivel Educativo y porcentaje de Ocupados, sólo Mujeres.}

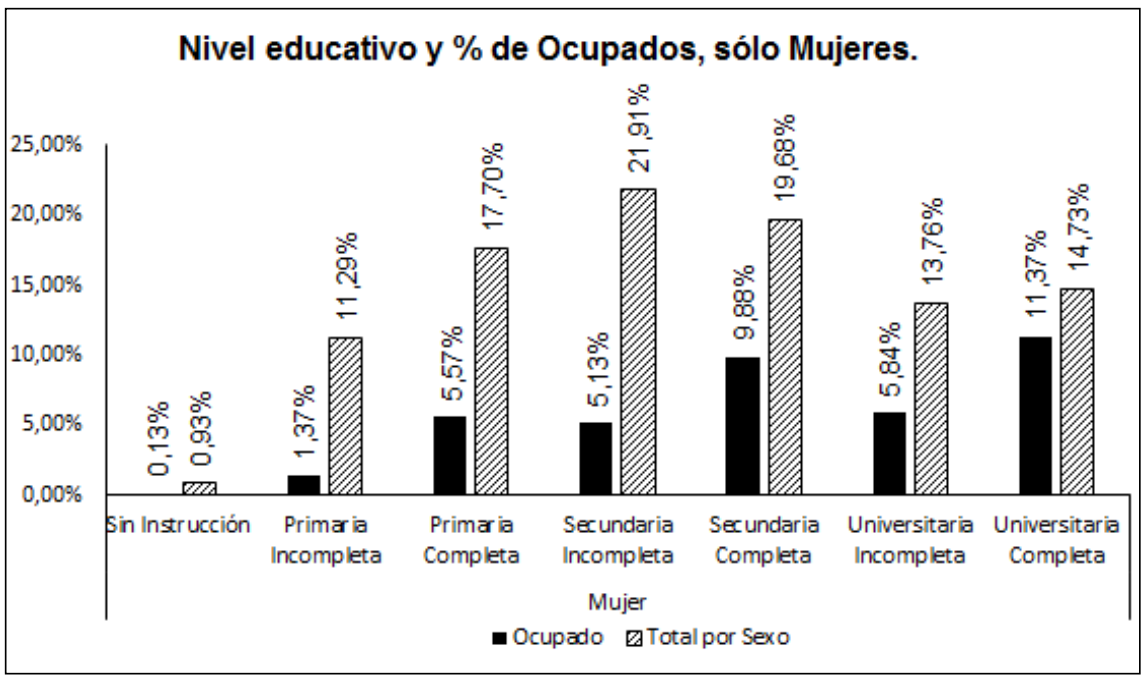

Fuente: Elaboración propia con datos de la EPH para el segundo trimestre de 2012. 
Gráfico 5. Nivel Educativo y porcentaje de Ocupados, sólo Varones.

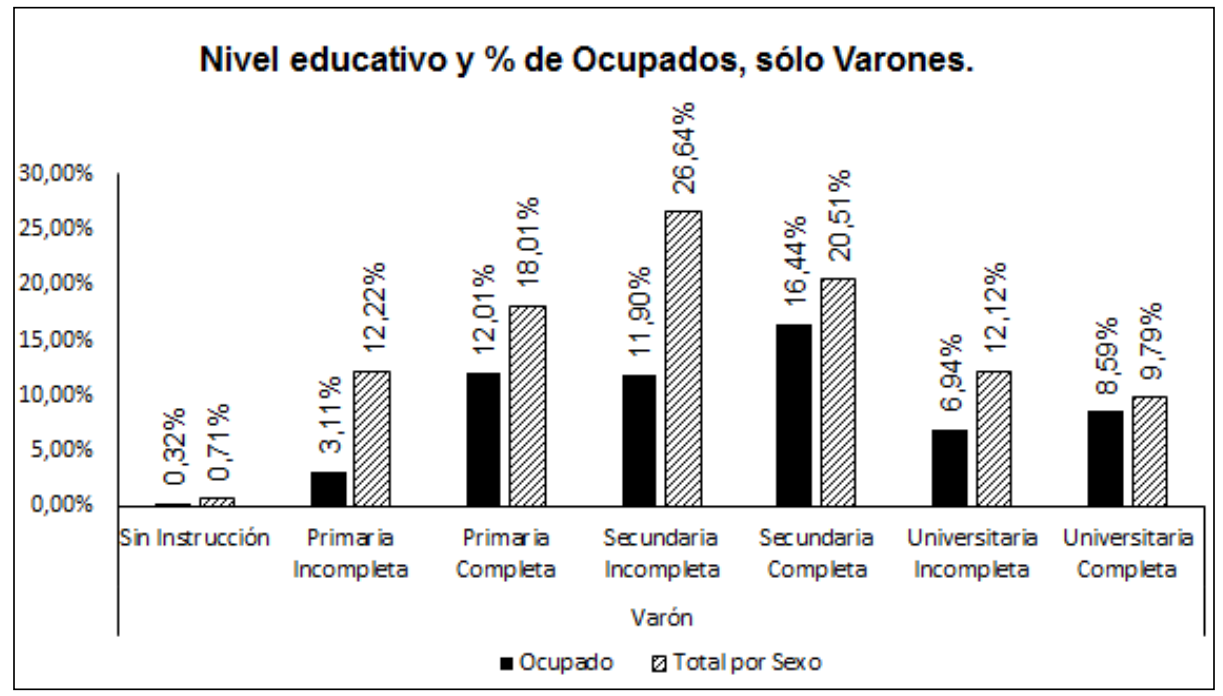

Fuente: Elaboración propia con datos de la EPH para el segundo trimestre de 2012.

Gráfico 6. Nivel Educativo según la calificación laboral exigida por el puesto en donde se encuentra ocupado, sólo mujeres.

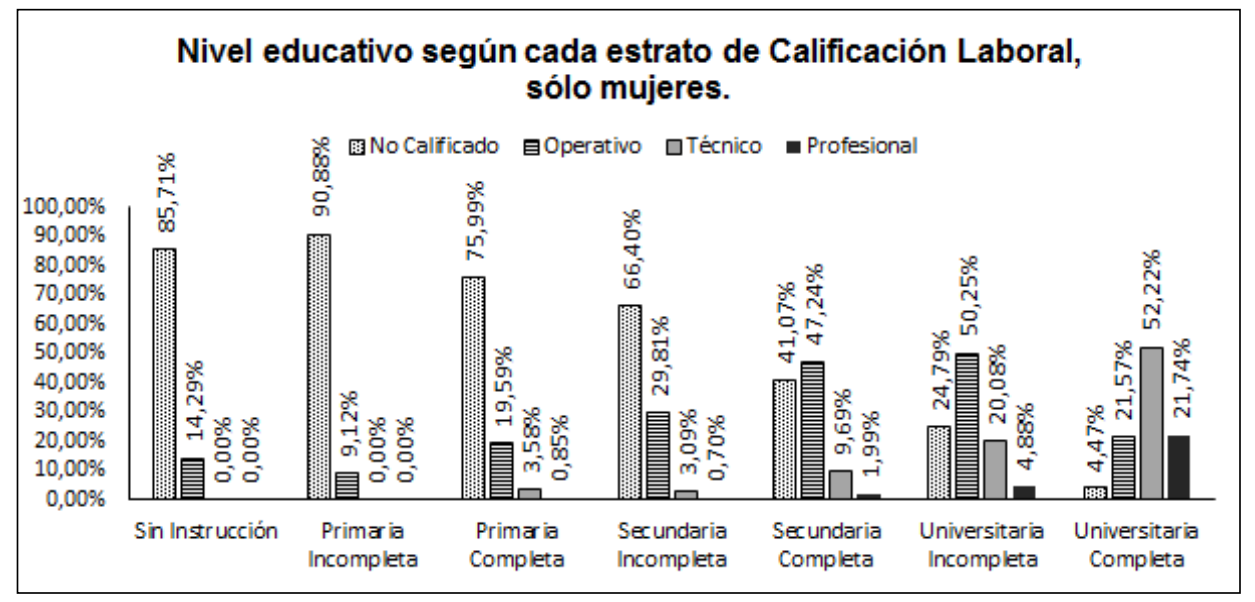

Fuente: Elaboración propia con datos de la EPH para el $2^{\circ}$ trimestre de 2012. 


\section{Gráfico 7. Nivel Educativo según la calificación laboral exigida por el puesto en donde se encuentra ocupado, sólo varones.}

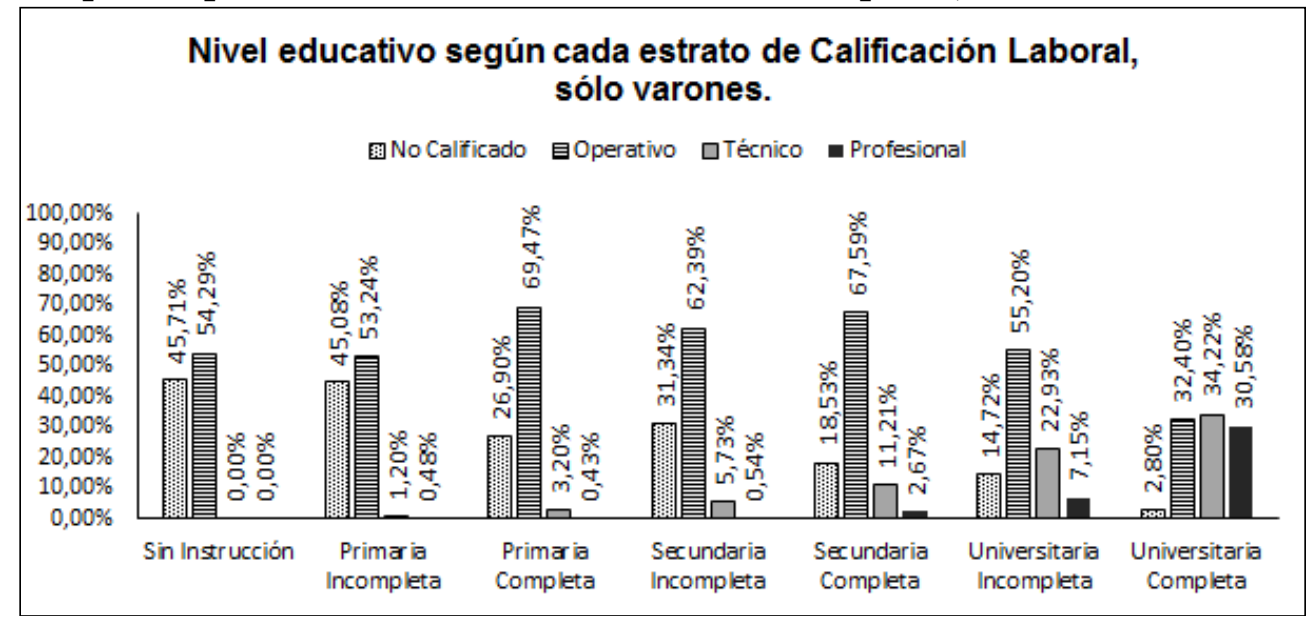

Fuente: Elaboración propia con datos de la EPH para el $2^{\circ}$ trimestre de 2012.

Resulta importante distinguir entre calificación laboral y nivel educativo de los individuos. La calificación laboral se refiere a las exigencias del puesto u ocupación que el individuo está ejerciendo actualmente, y éste puede estar sub o sobre-calificado para desempeñarse en el mismo, en parte según su nivel educativo. Esta situación obedece a que las mujeres se concentran en puestos de menor calificación laboral en los niveles educativos más bajos. Se observa una baja participación de las mujeres en puestos con la calificación "Operativo" y una mayor participación en puestos "No calificados", independientemente del nivel educativo alcanzado (a excepción del nivel universitario), (ver Gráficos 6 y 7).

En resumen, las mujeres muestran un mayor nivel educativo, en relación a los varones. Sin embargo, tanto la participación en el mercado laboral, como la intensidad con que ésta se expresa (en términos de horas semanales trabajadas) son menores para las mujeres que para los varones. Además, la educación como mecanismo de señalización para acceder a puestos de trabajo más calificados parece ser más sensible en los varones que en las mujeres.

Esta situación puede estar explicando parte de la escasa participación en el ingreso de las mujeres. Sin embargo, en este resultado juegan factores clave como la discriminación en el acceso al empleo, la segregación ocupacional y la discriminación en los ingresos. Todos estos factores potencian la escasa participación de las mujeres en el ingreso, y a 
su vez influyen en la baja tasa de participación en el mercado laboral. En las siguientes secciones se analizarán en detalle estos aspectos.

\section{Metodología y fuentes de datos}

A los fines de analizar la brecha en los salarios promedio por género, se aplica la técnica de descomposición contra-fáctica llamada descomposición Blinder-Oaxaca popularizada por Blinder (1973) y Oaxaca (1973).

En el estudio del diferencial de ingresos por grupos, es muy probable que exista un sesgo de selección muestral, dado que los trabajadores incluidos en los distintos grupos pueden no ser representativos de la población con características similares a aquellas que determinan el tipo o la calidad del puesto de trabajo. Los salarios se observan únicamente en las personas que están participando en el mercado laboral y este puede ser un grupo selectivo. Dada la existencia de bajas tasas de participación femenina en la fuerza laboral, la presencia de sesgo de selección puede introducir una sobreestimación en relación al efecto de las variables independientes, particularmente aquellas asociadas al capital humano, sobre los ingresos de las mujeres. Esta sobreestimación puede ser mayor que la asociada con el sesgo de selección en los varones, precisamente debido a las diferencias en la participación de ambos grupos.

Por otro lado, la sobre-estimación empírica de los ingresos estimados debería derivar del supuesto aceptable de que la población incluida en la muestra es relativamente más capital humana intensiva que la población realmente excluida. Esto implicaría que los ingresos promedio de la muestra sean mayores. La medición de la brechas de ingresos por género que no considere el problema del sesgo de selección corre un serio riesgo de subestimar del efecto de la discriminación. En consecuencia, en presencia de este sesgo de selección muestral las estimaciones por Mínimos Cuadrados Ordinarios (MCO) resultan en estimadores sesgados e inconsistentes (Heckman, 1979). Ante este problema, en el presente artículo se incluirá una corrección por sesgo de selección muestral en las ecuaciones de ingresos a través del procedimiento de Heckman (1976, 1979).

En base a lo anterior, en primer lugar se calcula para cada género el siguiente modelo Probit a los fines de conocer la probabilidad de que una persona participe o no del mercado de trabajo:

$$
p\left(\mathrm{~s}_{g}=1 \mid \mathbf{G}\right)=\Phi(\mathbf{G} \delta)
$$


Donde:

- s es la condición de ingreso al mercado laboral y g indica el sexo de los individuos en la sub-muestra.

- G es un vector de características personales y familiares.

- $\Phi$ es la función de distribución acumulada de la distribución normal.

- $\delta$ es un vector de parámetros desconocidos

Posteriormente se calcula, también para cada género, la siguiente regresión mediante mínimos cuadrados ordinarios, incluyendo los resultados obtenidos del modelo probit como una variable explicativa:

$$
\ln \left(\mathbf{Y}_{\boldsymbol{g}}\right)=\beta_{0}+\sum_{i=1}^{n} \beta_{i} \mathbf{X}+\sum_{r=(n+1)}^{t} \beta_{r} \mathbf{E}+\sum_{s=(t+1)}^{k} \beta_{s} \mathbf{Z}
$$

Donde:

- Y es un vector que recoge el logaritmo del ingreso neto por hora de cada individuo en la sub-muestra, y $g$ indica el sexo de los individuos que integran el subconjunto.

- X es una matriz que recoge las características personales de cada individuo en la muestra.

- E es una matriz que expresa el nivel educativo alcanzado.

- $\mathbf{Z}$ es una matriz que contiene características del puesto de trabajo en donde se desempeña el individuo.

El procedimiento de descomposición Blinder-Oaxaca divide el diferencial de ingresos en dos grupos, una parte explicada por las diferencias de grupo en las características de productividad tales como educación o experiencia en el trabajo; y una parte residual que no se puede explicar por tales diferencias en los determinantes salariales. La parte no explicada es usualmente empleada como una medida de discriminación, pero también incluye el efecto de las diferencias grupales en los predictores inobservables (residuo). Por lo tanto, luego de estimar las ecuaciones de ingreso para ambos géneros, se procede a analizar qué parte del diferencial en el ingreso promedio por hora se explica por las diferencias en los predictores:

$$
D=E\left(Y_{h}\right)-E\left(Y_{m}\right)=E\left(X_{h}\right)^{\prime} \beta_{h}-E\left(X_{m}\right)^{\prime} \beta_{m}
$$

Donde:

- $E\left(Y_{m}\right)=E\left(X_{m}\right)^{\prime} \beta_{m}$ es el ingreso promedio por hora para las mujeres. 

varones.

- $E\left(Y_{h}\right)=E\left(X_{h}\right)^{\prime} \beta_{h}$ es el ingreso promedio por hora para los

Para ello, se descompone la ecuación anterior en tres partes:

$$
\begin{array}{r}
D=\left[E\left(X_{h}\right)-E\left(X_{m}\right)\right]^{\prime} \beta_{m}+E\left(X_{m}\right)^{\prime}\left(\beta_{h}-\beta_{m}\right) \\
+\left[E\left(X_{h}\right)-E\left(X_{m}\right)\right]^{\prime}\left(\beta_{h}-\beta_{m}\right)
\end{array}
$$

El primer término de la ecuación anterior corresponde a las diferencias grupales en los predictores (el efecto dotación). Las diferencias de ingreso observadas aquí corresponden a características observables capturadas en los predictores. El segundo término de la ecuación mide la contribución de las diferencias en los coeficientes (incluyendo diferencias en el intercepto) a las diferencias en el ingreso promedio. El tercer término capta la interacción debido a que las diferencias en las dotaciones y en los coeficientes existen simultáneamente entre los dos grupos. El término de interacción forma parte de la porción del diferencial de ingresos no explicada, atribuida a las características propias de la estructura del mercado de trabajo. Por ejemplo, la mujer acepta desde la entrada al mercado laboral un pago inferior al que se le ofrece al hombre (diferencias en las constantes) que sólo se explican por su condición de mujer. Es la interacción de la prima de ingresos con los niveles de capital humano no observados.

Para desarrollar la técnica se utiliza la EPH correspondiente al segundo trimestre del año 2012, elaborada por el Instituto Nacional de Estadísticas y Censos de la República Argentina (INDEC).

La variable dependiente será el logaritmo del ingreso neto por hora de la ocupación principal de los individuos. En el Anexo se detallan las variables utilizadas. Las principales modificaciones sobre esta base de datos consisten en la combinación con el Clasificador Nacional de Ocupaciones $(\mathrm{CNO})^{5}$ y la Clasificación de Actividades Económicas para Encuestas Sociodemográficas del MERCOSUR ${ }^{6}$ (CAES).

La variable pp04d_cod de la EPH corresponde al código de ocupación para aquellos individuos cuya condición de actividad es "ocupado". El mismo se compone de cinco dígitos que hacen referencia al CNO, y permite conocer, en cada individuo ocupado, los datos referidos a:

\footnotetext{
5 Consultar en:

http://www.indec.mecon.ar/ftp/cuadros/menusuperior/eph/EPHcontinua CNO2001 redu cido_09.pdf

${ }^{6}$ Consultar en:

http://www.indec.mecon.ar/ftp/cuadros/menusuperior/eph/caes_mercosur_1.0.pdf
} 
Carácter ocupacional ( $1^{\circ}$ y $2^{\circ}$ dígito), Jerarquía ocupacional ${ }^{7}$ ( $3^{\circ}$ dígito), Tecnología ocupacional ( $4^{\circ}$ dígito) y Calificación ocupacional ${ }^{8}\left(5^{\circ}\right.$ dígito). Se ha utilizado el tercer dígito de la variable pp04d_cod a los fines de generar variables dummy para cada jerarquía ocupacional (en donde el valor 1 hace referencia a la presencia de ésta jerarquía en el individuo). De igual manera, se utiliza el quinto dígito de la variable pp04d_cod para crear variables dummy en referencia a la calificación ocupacional de cada individuo ocupado en la base de datos. La variable pp04b_caes de la EPH corresponde al código de actividad económica de las ocupaciones de los individuos ocupados. Se utilizan los dos primeros dígitos de la codificación para asignar la ocupación del individuo a un sector económico, agrupados en: Sector Primario, Servicios, Industria y Construcción, Comercio, Finanzas y Varios. El resto de las variables utilizadas se encuentran directamente en la EPH, o son simples transformaciones lineales de éstas.

\section{Resultados}

Los resultados de la descomposición de Oaxaca-Blinder sobre el logaritmo del ingreso neto por hora, con corrección por sesgo de selección muestral y segregación horizontal y vertical, se presentan en el primer panel del Cuadro $1^{9}$. Allí se observan las predicciones promedio para la variable dependiente y sus diferencias por grupo. La media del logaritmo de los ingresos netos por hora es de 2,820 para las mujeres y de 2,849 para los varones, dando como resultado una brecha de ingreso de -0,029. Si bien las especificaciones de los modelos son diferentes, este resultado contrasta con los hallados por Esquivel y Paz (2005) quienes concentraron el análisis en los ingresos horarios de los asalariados. Para estos autores, la serie histórica de salarios horarios por género ha mostrado brechas salariales favorables a las mujeres, un rasgo constante y sorprendente del mercado de trabajo argentino que se reflejaba ya en el año 2003.

En el segundo panel del Cuadro 1 se observa la descomposición del ingreso en tres partes. La primera parte es positiva e indica el incremento medio en el ingreso de los varones cuando se aplica a éstos las dotaciones de las mujeres. Del diferencial de ingresos, esta proporción explica el

\footnotetext{
${ }^{7}$ El tercer dígito de la clasificación reflejada en la variable pp04b_cod puede asumir sólo los siguientes valores: Dirección $=0$, Cuenta Propia $=1$, Jefes $=2$, Asalariados $=3$

${ }^{8}$ El quinto dígito de la clasificación reflejada en la variable pp04b_cod puede asumir sólo los siguientes valores: profesionales $=1$, técnicos $=2$, operativos $=3$, no calificados $=4$

9 Para la estimación del modelo se ha utilizado el módulo desarrollado por Ben Jann para Stata Statistical Software de StataCorp LP (Jann, 2008).
} 
$41,62 \%{ }^{10}$. La proporción atribuida a los coeficientes, que detalla el efecto sobre el ingreso medio de los varones cuando se aplican sobre éstos los coeficientes de las mujeres, es negativa y explica el 54,97\% de la brecha. Es decir, la brecha de ingresos no es favorable a las mujeres por la penalidad en los retornos que ellas reciben. El diferencial de ingresos sería favorable a las mujeres si las características de las mujeres fueran remuneradas a los "precios" de los varones. El efecto simultáneo de las dotaciones y los coeficientes es de 0,01 y explica un 3,4\% de la brecha en el logaritmo de los ingresos por hora, pero el mismo no es significativo.

\begin{tabular}{|c|c|c|c|c|c|c|}
\hline LogYhora & Coef & E.E. & $\mathbf{z}$ & $\mathrm{P}>|\mathrm{z}|$ & \multicolumn{2}{|c|}{ [95\% Int.Conf.] } \\
\hline \multicolumn{7}{|l|}{ Diferencial } \\
\hline Mujer & 2,820 & 0,012 & 237,190 & 0,000 & 2,797 & 2,843 \\
\hline Varón & 2,849 & 0,008 & 371,490 & 0,000 & 2,834 & 2,864 \\
\hline Diferencia & $-0,029$ & 0,014 & $-2,070$ & 0,039 & $-0,057$ & $-0,001$ \\
\hline \multicolumn{7}{|c|}{ Descomposición } \\
\hline Dotaciones & 0,122 & 0,008 & 15,620 & 0,000 & 0,107 & 0,138 \\
\hline Coeficientes & $-0,162$ & 0,015 & $-10,830$ & 0,000 & $-0,191$ & $-0,132$ \\
\hline $\begin{array}{l}\text { Interacción } \\
\mathrm{N}=21939\end{array}$ & 0,010 & 0,013 & 0,750 & 0,456 & $-0,016$ & 0,036 \\
\hline
\end{tabular}

Fuente: Elaboración propia con datos de la EPH para el segundo trimestre de 2012.

\begin{tabular}{|c|c|c|c|c|c|c|}
\hline \multicolumn{7}{|c|}{$\begin{array}{r}\text { Cuadro 2 - Descomposición de Oaxaca-Blinder c } \\
\text { Pesos Argentinos neto por hora. }\end{array}$} \\
\hline Mujer & 16,780 & 0,200 & 237,190 & 0,000 & 16,393 & 17,176 \\
\hline Varón & 17,278 & 0,133 & 371,490 & 0,000 & 17,020 & 17,539 \\
\hline Diferencia & 0,971 & 0,014 & $-2,070$ & 0,039 & 0,945 & 0,999 \\
\hline \multicolumn{7}{|c|}{ Descomposición } \\
\hline Dotaciones & 1,130 & 0,009 & 15,620 & 0,000 & 1,113 & 1,148 \\
\hline Coeficientes & 0,851 & 0,013 & $-10,830$ & 0,000 & 0,826 & 0,877 \\
\hline Interacción & 1,010 & 0,014 & 0,750 & 0,456 & 0,984 & 1,037 \\
\hline
\end{tabular}

Fuente: Elaboración propia con datos de la EPH para el segundo trimestre de 2012.

${ }_{10}$ El porcentaje se calcula sobre la suma absoluta de la descomposición. 
Si bien estos resultados están expresados en una escala logarítmica, son sensibles a transformaciones de los resultados a la escala original (en pesos argentinos), tal como se detalla en el Cuadro 2. La media de los ingresos horarios es de 16,780 pesos argentinos para las mujeres y de 17,278 para los varones, dando como resultado una brecha de ingreso por hora de 0,971 a favor de éstos últimos. Es decir, el ingreso por hora de las mujeres es igual a un $97,11 \%$ del ingreso por hora de los varones. El ajuste en los ingresos por hora de los varones, si es que éstos tuviesen las mismas dotaciones que las mujeres, implicaría un aumento del 13\%. Por otro lado, el ingreso por hora de los varones sería sólo de un 85,08\% de su nivel actual si se aplicara sobre éstos los mismos coeficientes estimados (retornos) para las mujeres.

De lo anterior debe resaltarse la situación de discriminación observada en el mercado laboral en contra de las mujeres, que están dotadas de mayor cantidad de capital humano que los varones, y la retribución que obtienen del mismo es relativamente menor.

La ecuación salarial de base que da soporte a estos resultados es la que se detalla en el Cuadro 3. Dada la brecha de ingresos favorable a los varones, interesa analizar si existen barreras a la entrada a ciertos sectores (segregación horizontal) o a ciertas ocupaciones (segregación vertical) entre varones y mujeres.

La presencia de segregación vertical o jerárquica, implica que las mujeres son negativamente seleccionadas en puestos de calidad ${ }^{11}$. Es decir, se excluye a las mujeres de puestos jerárquicos de mayor prestigio y salarios relativos. Para captar la segregación horizontal (vertical) se busca detectar si existen sectores de actividad económica (puestos jerárquicos) en donde la predominancia de mujeres induce a una disminución en las remuneraciones de todo el sector (puesto).

La mayor parte de las investigaciones desarrolladas sobre discriminación en el mercado laboral omiten a los trabajadores no asalariados debido a que las reglas de fijación de las remuneraciones no responden a las mismas reglas de mercado que los asalariados. Por esta razón, la EPH los considera como categorías excluyentes distinguiendo a los Asalariados de los Cuentapropistas, Dirección, y Jefes. Por lo tanto, es importante incluir la segregación ocupacional como determinante del ingreso. Además al estar planteado el modelo en logaritmos del ingreso, se

\footnotetext{
11 A diferencia de Esquivel (2007), quien estudia la existencia de barreras al acceso a puestos de trabajo de calidad como una adaptación de la noción de segregación vertical, en este trabajo se captura la segregación vertical en relación a los puestos jerárquicos ocupados.
} 


\section{Cuadro 3. Regresión logarítmica por género, variable dependiente $=$ Logaritmo del ingreso por hora .}

\begin{tabular}{lll}
\hline Variables & Mujer & Varón \\
\hline LogYhora & & \\
FEM_Vertical & $-1,390^{* *}$ & 0,245 \\
FEM_Horizontal & $-0,176^{* * *}$ & $-0,060^{* *}$ \\
Edad & $0,015^{* * *}$ & $0,018^{* * *}$ \\
Edad2 & $-0,000^{* * *}$ & $-0,000^{* * *}$ \\
Sin instrucción & & \\
Primaria completa & 0,028 & $0,153^{* * *}$ \\
Secundaria incompleta & $0,092^{* *}$ & $0,218^{* * *}$ \\
Secundaria completa & $0,230^{* * *}$ & $0,324^{* * *}$ \\
Universitaria incompleta & $0,318^{* * *}$ & $0,376^{* * *}$ \\
Universitaria completa & $0,453^{* * *}$ & $0,478^{* * *}$ \\
Hs. trabajadas por semana & $-0,005^{* * *}$ & $-0,004^{* * *}$ \\
Antigüedad menor 1 año & & \\
Antigüedad 1 a 5 años & $0,108^{* * *}$ & $0,092^{* * *}$ \\
Antigüedad mayor a 5 años & $0,205^{* * *}$ & $0,139^{* * *}$ \\
Pareja & $0,058^{* * *}$ & $0,050^{* * *}$ \\
Ocupado pleno & & \\
Subocupado demandante & $0,102^{* * *}$ & $0,059^{* * *}$ \\
Subocupado NO demandante & $0,138^{* * *}$ & $0,103^{* *}$ \\
Sobreocupado & $-0,268^{* * *}$ & $-0,208^{* *}$ \\
Trabajo Formal & $0,480^{* * *}$ & $0,409^{* * *}$ \\
Región = Patagonia & $-0,179^{* * * *}$ & $-0,266^{* * *}$ \\
Región = GBA & $-0,488^{* * *}$ & $-0,558^{* * *}$ \\
Región = NOA & $-0,538^{* * * *}$ & $-0,573^{* * *}$ \\
Región = NEA & $-0,437^{* * * *}$ & $-0,466^{* * *}$ \\
Región = Cuyo & $-0,245^{* * *}$ & $-0,314^{* * *}$ \\
Región = Pampeana & $-0,285^{* * * *}$ & $-0,201^{* * * *}$ \\
Jerarquía = Dirección & 0,018 & $0,146^{* * *}$ \\
Jerarquía = Cuentapropia & 0,050 & $-0,104$ \\
Jerarquía = Jefe & $0,505^{* * * *}$ & $0,494^{* * * *}$ \\
Jerarquía = Asalariado & $0,313^{* * *}$ & $0,273^{* * *}$ \\
NO Calificado & \\
Calificación = Profesional & & \\
Calificación = Técnico & \\
\hline & & \\
\hline
\end{tabular}




\begin{tabular}{lll}
\hline Calificación = Operativo & $0,089^{* * *}$ & $0,136^{* * *}$ \\
Constante & $2,824^{* * *}$ & $2,263^{* * *}$ \\
\hline $\mathrm{N}$ & 27548 & 25291 \\
Censored Obs & 18324 & 12576 \\
Uncensored Obs & 9224 & 12715 \\
Wald chi2(28) & $8189,710^{* * *}$ & $9846,070^{* * *}$ \\
$* * * * \mathrm{p}<0,001 ; * * \mathrm{p}<0,01$ & & \\
\hline
\end{tabular}

Fuente: Elaboración propia con datos de la EPH del segundo trimestre de 2012.

evitan las divergencias en las remuneraciones propias de las diferencias en las reglas de fijación de precios de las distintas categorías ocupacionales.

La variable FEM, que consiste en la distribución del empleo según género entre sectores económicos y jerarquías ocupacionales se emplea como indicador de la participación de las mujeres. Es decir, se calcula como el porcentaje de mujeres en cada uno de los sectores económicos o jerarquías ocupacionales. La variable FEM_Vertical consiste en el porcentaje de mujeres en cada jerarquía ocupacional. Se construye en base al tercer dígito del CNO aplicado a la EPH. La jerarquía ocupacional permite distinguir la existencia de las formas jerárquicas-organizativas de los procesos de trabajo. Esta dimensión reconoce cuatro categorías: dirección, cuenta propia, jefatura y trabajadores asalariados. La variable FEM_Horizontal, en tanto, captura el porcentaje de mujeres en cada sector de actividad económica. Se calcula en base a los dos primeros dígitos de la CAES aplicados a la EPH.

Como puede apreciarse en el Cuadro 3, para las mujeres la relación entre FEM_Vertical y los ingresos es negativa y significativa. Las mujeres ven disminuido el logaritmo de sus ingresos en categorías ocupacionales más feminizadas. Por cada punto de aumento en la proporción de mujeres en cada jerarquía ocupacional, el logaritmo del ingreso de éstas se reduce en un 139\%. Por el contrario, los varones no presentan cambios significativos en sus ingresos al trabajar en jerarquías ocupacionales feminizadas.

Por otro lado, la feminización de los sectores económicos implica un costo tanto para los varones como para las mujeres que trabajan en los mismos. Un incremento de un punto en la proporción de mujeres en un determinado sector económico implica una reducción del $17,6 \%$ en logaritmo de los ingresos por hora de las mujeres y del $6 \%$ en los varones. 
Cuadro 4. Correlaciones entre variables de Jerarquía Ocupacional y Calificación Laboral.

\begin{tabular}{|c|c|c|c|c|c|c|c|c|c|}
\hline & & \multicolumn{4}{|c|}{ Jerarquía Ocupacional } & \multicolumn{4}{|c|}{ Calificación Laboral } \\
\hline & & Dir. & Cta. Pr. & Jefes & Asal. & Prof. & Téc. & Oper. & No Calif. \\
\hline \multirow{4}{*}{$\begin{array}{l}\text { Jerarquía } \\
\text { Ocupacional }\end{array}$} & Dirección & 1 & & & & & & & \\
\hline & Cta. Propia & $-0.0206^{* x}$ & 1 & & & & & & \\
\hline & Jefe & $-0.0098^{*}$ & $-0.0383^{* * t}$ & 1 & & & & & \\
\hline & Asalariado & $-0.0486^{\text {ts }}$ & $-0.1904^{* x}$ & $-0.0904^{* *+}$ & 1 & & & & \\
\hline \multirow{4}{*}{$\begin{array}{l}\text { Calificación } \\
\text { Laboral }\end{array}$} & Profesional & $0.3655^{5 \times 2}$ & $0.0974^{4 *}$ & $0.2368^{* *}$ & $0.0739^{* *}$ & 1 & & & \\
\hline & Técnico & $-0.0184^{* *+}$ & $0.0675^{5 *}$ & $0.0373^{* *}$ & $0.2795^{5^{* 8}}$ & $-0.0504^{* *}$ & 1 & & \\
\hline & Operativo & $-0.0379^{4 * t}$ & $0.3564^{* *}$ & $0.0939^{2 *}$ & $0.4462^{2 s}$ & $-0.1037^{* *}$ & $-0.1329^{4 * t}$ & 1 & \\
\hline & No Calif. & $-0.0234^{*+*}$ & $-0.0433^{*+4}$ & $-0.0436^{* *}$ & $0.4544^{s *}$ & $-0.0640^{*+5}$ & $-0.0820^{*+*}$ & $-0.1687^{* * *}$ & 1 \\
\hline
\end{tabular}

Fuente: Elaboración propia con datos de la EPH del segundo trimestre de 2012.

Las variables dummies de calificación laboral y jerarquía ocupacional (que indican la presencia de segregación vertical y horizontal) están correlacionadas entre sí. La categoría profesionales está correlacionada significativa y positivamente con todas las categorías ocupacionales (Dirección, Cuenta-Propia, Jefes y Asalariados). Por su parte, las categorías técnico y operarios presentan una correlación negativa sólo con los puestos de Dirección. Dado que son variables relevantes en la estimación, su omisión puede introducir problemas en la misma.

Las categorías ocupacionales Cuentapropista y Jefe poseen un efecto significativo en la determinación del ingreso laboral, tomando Dirección como categoría base. Sin embargo, no es posible afirmar nada respecto a la incidencia de la categoría asalariado. Posiblemente, dado que es la categoría ocupacional más numerosa tanto en varones como en mujeres, su presencia no introduce cambios significativos.

A los fines de investigar si existen barreras a la entrada al mercado laboral para varones y mujeres; es decir, si las mujeres son, en términos relativos, negativamente seleccionadas para participar en el mercado laboral, se calcula la probabilidad de percibir un ingreso a partir de regresiones probit para varones y mujeres, en donde la variable dependiente toma valor 1 si los trabajadores declaran tener un ingreso proveniente de una ocupación principal, y cero en el caso contrario.

Tanto para varones como para mujeres, la probabilidad de observar ingresos provenientes de la ocupación principal mayores a cero está positivamente asociada a la edad, la formalidad en el trabajo, la cantidad de miembros en el hogar, la condición de depender del trabajo para vivir, la 
Cuadro 5. Regresión probit para la corrección de sesgo de selección muestral en las mujeres.

\begin{tabular}{|c|c|c|c|c|c|c|}
\hline & Coef. & E.E. & $\mathbf{z}$ & $\mathbf{P}>|\mathbf{z}|$ & \multicolumn{2}{|c|}{ [95\% Int. Conf.] } \\
\hline Sector $=$ Varios & Omitida & & & & & \\
\hline Sector $=$ Primario & 0,907 & 0,282 & 3,220 & 0,001 & 0,355 & 1,459 \\
\hline Sector $=$ Industria & 1,239 & 0,081 & 15,240 & 0,000 & 1,080 & 1,399 \\
\hline Sector $=$ Comercio & 1,696 & 0,053 & 31,950 & 0,000 & 1,592 & 1,800 \\
\hline Sector $=$ Finanzas & 0,946 & 0,192 & 4,920 & 0,000 & 0,569 & 1,322 \\
\hline Sector $=$ Servicios & 1,184 & 0,047 & 25,100 & 0,000 & 1,092 & 1,277 \\
\hline No Calificado & Omitida & & & & & \\
\hline Calificación = Profesional & 1,404 & 0,090 & 15,670 & 0,000 & 1,228 & 1,579 \\
\hline Calificación $=$ Técnico & 0,985 & 0,061 & 16,120 & 0,000 & 0,865 & 1,104 \\
\hline Calificación $=$ Operario & 1,306 & 0,048 & 26,980 & 0,000 & 1,211 & 1,401 \\
\hline Trabajan 5 personas o menos & Omitida & & & & & \\
\hline Trab. más de 500 personas & 0,199 & 0,119 & 1,660 & 0,096 & $-0,035$ & 0,433 \\
\hline Trab. de 200 a 500 personas & 0,176 & 0,116 & 1,520 & 0,128 & $-0,051$ & 0,403 \\
\hline Trab. de 101 a 199 personas & $-0,075$ & 0,109 & $-0,690$ & 0,490 & $-0,289$ & 0,138 \\
\hline Trab. de 41 a 100 personas & 0,023 & 0,091 & 0,260 & 0,796 & $-0,154$ & 0,201 \\
\hline Trab. de 26 a 40 personas & 0,069 & 0,097 & 0,710 & 0,476 & $-0,121$ & 0,258 \\
\hline Trab. de 6 a 25 personas & 0,227 & 0,063 & 3,580 & 0,000 & 0,103 & 0,351 \\
\hline Trabajo Formal & 1,109 & 0,046 & 24,190 & 0,000 & 1,019 & 1,199 \\
\hline Edad & 0,010 & 0,001 & 12,850 & 0,000 & 0,008 & 0,011 \\
\hline Menores en el hogar & $-0,121$ & 0,015 & $-7,850$ & 0,000 & $-0,151$ & $-0,091$ \\
\hline Miembros del hogar & 0,071 & 0,007 & 9,610 & 0,000 & 0,057 & 0,086 \\
\hline Inquilino & 0,041 & 0,034 & 1,210 & 0,228 & $-0,026$ & 0,107 \\
\hline ¿Vive del trabajo? & 0,950 & 0,044 & 21,820 & 0,000 & 0,864 & 1,035 \\
\hline Jefe de hogar & 0,594 & 0,033 & 17,780 & 0,000 & 0,529 & 0,660 \\
\hline Ingreso familiar & 0,000 & 0,000 & $-14,260$ & 0,000 & 0,000 & 0,000 \\
\hline Ingreso NO laboral & 0,000 & 0,000 & $-14,250$ & 0,000 & 0,000 & 0,000 \\
\hline Años de escolaridad & 0,029 & 0,003 & 8,550 & 0,000 & 0,022 & 0,035 \\
\hline Constante & $-2,832$ & 0,068 & $-41,880$ & 0,000 & $-2,965$ & $-2,700$ \\
\hline$\lambda$ Mills & 0,088 & 0,021 & 4,190 & 0,000 & 0,048 & 0,130 \\
\hline
\end{tabular}

Fuente: Elaboración propia con datos de la EPH para el segundo trimestre de 2012. 


\section{Cuadro 6. Regresión probit para la corrección de sesgo de selección muestral en los varones.}

\begin{tabular}{|c|c|c|c|c|c|c|}
\hline & Coef. & E.E. & $\mathbf{z}$ & $\mathbf{P}>|\mathbf{z}|$ & \multicolumn{2}{|c|}{ [95\% Int. Conf.] } \\
\hline & & & & & & \\
\hline Sector $=$ Primario & 1,097 & 0,099 & 11,100 & 0,000 & 0,903 & 1,291 \\
\hline Sector $=$ Industria & 2,017 & 0,044 & 45,450 & 0,000 & 1,930 & 2,104 \\
\hline Sector $=$ Comercio & 2,284 & 0,049 & 46,220 & 0,000 & 2,187 & 2,381 \\
\hline Sector $=$ Finanzas & 2,138 & 0,367 & 5,820 & 0,000 & 1,419 & 2,858 \\
\hline Sector $=$ Servicios & 1,856 & 0,058 & 32,200 & 0,000 & 1,743 & 1,969 \\
\hline NO Calificado & Omitida & & & & & \\
\hline Calificación = Profesional & 1,720 & 0,097 & 17,710 & 0,000 & 1,530 & 1,910 \\
\hline Calificación $=$ Técnico & 1,722 & 0,070 & 24,580 & 0,000 & 1,584 & 1,859 \\
\hline Calificación $=$ Operario & 1,276 & 0,040 & 31,830 & 0,000 & 1,198 & 1,355 \\
\hline Trab. 5 personas o menos & Omitida & & & & & \\
\hline Trab. más de 500 personas & 0,311 & 0,093 & 3,350 & 0,001 & 0,129 & 0,493 \\
\hline Trab. de 200 a 500 personas & 0,406 & 0,103 & 3,940 & 0,000 & 0,204 & 0,608 \\
\hline Trab. de 101 a 199 personas & 0,400 & 0,100 & 3,990 & 0,000 & 0,203 & 0,597 \\
\hline Trab. de 41 a 100 personas & 0,493 & 0,090 & 5,460 & 0,000 & 0,316 & 0,670 \\
\hline Trab. de 26 a 40 personas & 0,473 & 0,103 & 4,590 & 0,000 & 0,271 & 0,675 \\
\hline Trab. de 6 a 25 personas & 0,390 & 0,059 & 6,580 & 0,000 & 0,274 & 0,507 \\
\hline Trabajo Formal & 0,937 & 0,049 & 19,160 & 0,000 & 0,841 & 1,033 \\
\hline Edad & 0,006 & 0,001 & 4,790 & 0,000 & 0,003 & 0,008 \\
\hline Menores en el hogar & $-0,040$ & 0,020 & $-1,970$ & 0,049 & $-0,081$ & 0,000 \\
\hline Miembros del hogar & 0,042 & 0,010 & 4,220 & 0,000 & 0,022 & 0,061 \\
\hline Inquilino & $-0,003$ & 0,046 & $-0,070$ & 0,947 & $-0,093$ & 0,087 \\
\hline ¿Vive del trabajo? & 0,610 & 0,061 & 9,990 & 0,000 & 0,490 & 0,730 \\
\hline Jefe de hogar & 0,129 & 0,045 & 2,840 & 0,004 & 0,040 & 0,219 \\
\hline Ingreso familiar & 0,000 & 0,000 & $-6,520$ & 0,000 & 0,000 & 0,000 \\
\hline Ingreso NO laboral & 0,000 & 0,000 & $-6,680$ & 0,000 & 0,000 & 0,000 \\
\hline Años de escolaridad & 0,047 & 0,005 & 10,370 & 0,000 & 0,038 & 0,056 \\
\hline constante & $-2,957$ & 0,091 & $-32,510$ & 0,000 & $-3,135$ & $-2,778$ \\
\hline$\lambda$ Mills & $-0,074$ & 0,023 & 3,290 & 0,001 & $-0,119$ & $-0,030$ \\
\hline
\end{tabular}

Fuente: Elaboración propia con datos de la EPH para el segundo trimestre de 2012. 
condición de ser jefe de hogar y la cantidad de años de escolaridad finalizados (Cuadros 5 y 6). A su vez, esta probabilidad se asocia negativamente con la cantidad de menores en el hogar, el ingreso familiar y el ingreso no laboral. Los coeficientes representativos del sector económico son significativos y positivos en ambos casos. La misma situación se observa en las variables asociadas a la calificación laboral, siendo la variable de control representativa de personas no calificadas. En lo referido al tamaño de los establecimientos, los coeficientes son positivos en todos los casos, siendo la variable de control la que capta los establecimientos en donde trabajan 5 personas o menos.

En base a estas regresiones, se calcula el valor de lambda, también llamado Ratio de Mills, con el objetivo de corregir la estimación de los ingresos medios de varones y mujeres por el sesgo de selección en la muestra. En el período bajo análisis, los valores medios de lambda son mayores para las mujeres que para los varones, lo cual implica que las mujeres poseen menores probabilidades relativas a los varones de generar un ingreso positivo. El signo negativo de lambda indica que el sesgo de selección muestral tiende a sobrestimar el ingreso de los varones no ocupados de la muestra (o a subestimar el ingreso de los varones ocupados). Es decir, el salario de reserva de los individuos que no están trabajando actualmente es mayor que el de los individuos que sí están trabajando.

\subsection{El papel de la corrección de sesgos en la estimación}

Es importante destacar la importancia de la corrección del sesgo de selección muestral y la consideración de la segregación horizontal y vertical y su impacto sobre los resultados del modelo. De omitir estas correcciones, la brecha de ingresos por hora sería favorable a las mujeres, producto de una sobre-estimación del ingreso de éstas y una subestimación del ingreso por hora de los varones.

Como se muestra en el Cuadro 7, cuando se considera únicamente el sesgo de selección muestral el ingreso estimado para las mujeres cae un $2,37 \%$ respecto a la situación en donde no se considera ninguna de éstas correcciones. En cuanto a los varones, el ingreso promedio por hora estimado luego de la corrección es un 1,33\% superior a la situación observada sin correcciones. Es decir, luego de la corrección del sesgo de selección muestral, la brecha de ingresos se vuelve en contra de las mujeres, dado que su ingreso estimado disminuye mientras que el ingreso estimado para los varones aumenta. 


\section{Cuadro 7 - Evolución de los resultados mediante corrección de sesgos.}

\begin{tabular}{|c|c|c|c|c|c|c|}
\hline Modelo & Mujer & Varón & Dif. & Dotac. & Coef. & Interac. \\
\hline \multicolumn{7}{|l|}{ En Pesos: } \\
\hline $\begin{array}{l}\text { Sin Corrección por sesgo de } \\
\text { selección }\end{array}$ & 17,373 & 17,022 & $1,020^{* * *}$ & $1,154^{* * *}$ & $0,838^{* * *}$ & $1,055^{* * *}$ \\
\hline $\begin{array}{l}\text { Con corrección por sesgo de } \\
\text { selección }\end{array}$ & 16,962 & 17,248 & $0,983^{*}$ & $1,145^{* * *}$ & $0,825^{\text {** }}$ & 1,049 \\
\hline $\begin{array}{l}\text { Con corrección por sesgo de } \\
\text { selección, segregación vertical y } \\
\text { segregación horizontal }\end{array}$ & 16,780 & 17,278 & $0,971^{*}$ & $1,130^{* * *}$ & $0,851^{* * *}$ & 1,010 \\
\hline \multicolumn{7}{|l|}{ En logaritmo del Ingreso: } \\
\hline $\begin{array}{l}\text { Sin Corrección por sesgo de } \\
\text { selección }\end{array}$ & 2,855 & 2,835 & $0,020^{* *}$ & $0,143^{* * *}$ & $-0,177^{* * *}$ & $0,054^{* * *}$ \\
\hline $\begin{array}{l}\text { Con corrección por sesgo de } \\
\text { selección }\end{array}$ & 2,831 & 2,848 & $-0,017^{*}$ & $0,136^{* * *}$ & $-0,192^{* *}$ & 0,040 \\
\hline $\begin{array}{l}\text { Con corrección por sesgo de } \\
\text { selección, segregación vertical y } \\
\text { segregación horizontal } \\
* * * p<0,001 ;{ }^{* *} p<0,01 ;{ }^{*} p<0,1\end{array}$ & 2,820 & 2,849 & $-0,029^{*}$ & $0,122^{* * *}$ & $-0,162^{* * *}$ & 0,010 \\
\hline
\end{tabular}

Fuente: Elaboración propia en base a datos de la EPH para el segundo trimestre de 2012

\section{Cuadro 8 - Evolución de los resultados mediante corrección de} sesgos.

\begin{tabular}{lcc}
\hline Modelo & $\lambda$ Mills Mujer & $\lambda$ Mills Varón \\
\hline Sin Corrección por sesgo de selección & & \\
Con corrección por sesgo de selección & $0,055^{* *}$ & $-0,084^{* *}$ \\
Con corrección por sesgo de selección, segregación & $0,088^{* * *}$ & $-0,074^{* *}$ \\
vertical y segregación horizontal & & \\
$* * * p<0,001 ; * * p<0,01 ; * p<0,1$ & & \\
\hline
\end{tabular}

Fuente: Elaboración propia con datos de la EPH para el segundo trimestre de 2012

El impacto sobre los resultados es aún mayor cuando se incluye en el modelo la segregación horizontal y vertical. Luego de incluir éstas variables en el modelo, junto a la corrección por sesgo de selección muestral detallada en el párrafo anterior, el ingreso neto por hora estimado para las mujeres está en un nivel del $3,41 \%$ por debajo de la estimación sin correcciones, en tanto que el ingreso estimado para los hombres es un 1,50\% superior. Paralelamente a este aumento en la brecha de ingresos, la parte del diferencial que se explica por dotaciones disminuye, y aumenta la incidencia del cambio en los coeficientes, reduciendo los incentivos que las mujeres tienen de invertir en capital humano. 
Además, luego de la incorporación al modelo de las variables que captan la segregación ocupacional, el ratio de Mills correspondiente a las mujeres aumenta en mayor proporción que el de los varones, indicando que las probabilidades de las mujeres de generar ingresos mayores que cero son aún menores en relación a los varones, tal como se observa en el Cuadro 8.

\subsection{Estimación del modelo sólo para obreros o empleados}

Como puede apreciarse en el Cuadro 9, los ingresos por hora promedio son mayores, tanto para varones como mujeres, cuando se considera sólo a los obreros o empleados en relación de dependencia dentro del modelo (sólo asalariados). El aumento en el ingreso por hora es de 7,19\% en las mujeres y 7,69\% en los varones. Este aumento proporcionalmente mayor en el ingreso de los varones ocasiona que la brecha sea mayor que en el modelo que abarca la totalidad de personas que generan ingresos positivos. De hecho, la brecha de ingresos pasa de $97,11 \%$ a $96,67 \%$.

\section{Cuadro 9. Comparación de resultados entre total de personas con ingresos mayores a cero y sólo obreros o empleados.}

\begin{tabular}{|c|c|c|c|c|c|c|c|}
\hline Modelo & & Mujer & Varón & Dif. & Dotac. & Coef. & Interac \\
\hline \multicolumn{8}{|l|}{ En Pesos: } \\
\hline $\begin{array}{l}\text { Total con ingreso } \\
\text { ocupación principal }>0\end{array}$ & de & 16,780 & 17,278 & $0,971^{*}$ & $1,130^{* * *}$ & $0,851^{* * *}$ & $1,010^{*}$ \\
\hline Sólo obrero o empleado & & 17,987 & 18,606 & $0,966^{*}$ & $1,128^{* * *}$ & $0,890^{* * *}$ & 0,961 \\
\hline $\begin{array}{l}\text { En Logaritmo } \\
\text { Ingreso: }\end{array}$ & del & & & & & & \\
\hline $\begin{array}{l}\text { Total con ingreso } \\
\text { ocupación principal }>0\end{array}$ & de & 2,820 & 2,849 & $-0,029^{*}$ & $0,122^{* * *}$ & $-0,161^{* * *}$ & $0,010^{*}$ \\
\hline $\begin{array}{l}\text { Sólo obrero o empleado } \\
* * * p<0,01 ; * p<0,1\end{array}$ & & 2,889 & 2,923 & $-0,338^{*}$ & $0,120^{* * *}$ & $-0,115^{* * *}$ & $-0,038$ \\
\hline
\end{tabular}

Fuente: Elaboración propia en base a datos de la EPH para el segundo trimestre de 2012.

En el modelo que incluye sólo asalariados, la proporción de la brecha de ingresos explicada por el efecto de las dotaciones tiene una mayor participación que los coeficientes en la explicación de la brecha de ingresos comparado al modelo que incluye la totalidad de los trabajadores que generan ingresos.

En el Cuadro 10 puede apreciarse que, al considerar sólo asalariados en el modelo, el valor del ratio de Mills correspondiente a las mujeres disminuye, mientras que el correspondiente a los varones 
aumenta. Esto implica un incremento relativo en la probabilidad de encontrar mujeres con ingresos mayores a cero. Es decir, la probabilidad que tienen las mujeres de incorporarse al mercado laboral es mayor cuando consideramos sólo obreros o empleados en relación de dependencia (asalariados) que cuando contemplamos la totalidad de los trabajadores (asalariados y no asalariados).

En consecuencia, la brecha de ingresos aumenta cuando se considera sólo a los trabajadores asalariados. Sin embargo, la parte de la brecha explicada por diferencias en los coeficientes (asociada a la discriminación) disminuye notablemente. Adicionalmente, aumenta considerablemente la parte de la brecha de ingresos explicada por el efecto conjunto de las diferencias en las dotaciones y los coeficientes. Paralelamente a éstos resultados, la probabilidad de que una mujer se sume al mercado laboral es mayor cuando se consideran sólo los trabajadores asalariados.

\section{Cuadro 10. Comparación de los resultados entre Asalariados y} Total.

\begin{tabular}{lcc}
\hline Modelo & $\lambda$ Mills Mujer & $\lambda$ Mills Varón \\
\hline Total con ingreso de ocupación principal $>0$ & $0,088^{* * *}$ & $-0,074^{* *}$ \\
Sólo obrero o empleado & $0,063^{* *}$ & $-0,116^{* *}$ \\
${ }^{* *} \mathrm{p}<0,01 ;{ }^{*} \mathrm{p}<0,1$ & & \\
\hline
\end{tabular}

Fuente: Elaboración propia con datos de la EPH para el segundo trimestre de 2012

\section{Consideraciones finales}

El objetivo de este trabajo fue analizar la existencia de ingresos desiguales por género en Argentina. Con vistas a este objetivo, se aplicó el método de descomposición de Blinder (1973) y Oaxaca (1973), el cual desagrega la diferencia en el logaritmo del ingreso horario de cada género en: a) diferencia en características personales y atributos del trabajo, b) diferencia en coeficientes. Los principales resultados obtenidos del trabajo se resumen en:

Las probabilidades de encontrar mujeres con ingresos positivos son menores que en el caso de los varones. Esta situación se explica, en parte, por la consideración de variables propias del hogar (cantidad de hijos, miembros del hogar, ingreso familiar, entre otras) en conjunto con variables 
que captan características personales (edad, años de escolaridad, entre las más relevantes) y variables propias del mercado laboral (sector de actividad, tamaño del establecimiento, formalidad del empleo)

La diferencia en el logaritmo del ingreso horario total resultó levemente favorable para los varones. El principal componente que explica esta diferencia es el efecto coeficientes. Esto implica que los varones ocupados poseen mejores remuneraciones respecto de las mujeres con iguales dotaciones de capital humano.

Respecto a los determinantes del ingreso, mientras que en las mujeres la segregación vertical reduce el ingreso horario, en el grupo de los varones la segregación vertical no es significativa en la determinación de los ingresos. Es decir, la feminización de una jerarquía ocupacional penaliza a las mujeres que ostentan la misma, no así a los varones.

La segregación horizontal presenta un efecto negativo en la determinación de los ingresos. Cuanto mayor es la participación de las mujeres por sector ocupacional, menor es el ingreso horario percibido tanto para varones como para mujeres, aunque el efecto es más fuerte para éstas últimas.

El resto de las variables consideradas son significativas y presentan la misma dirección en ambos géneros. Las variables representativas del nivel educativo tienen un impacto significativo y positivo en la determinación del ingreso horario, y los coeficientes son mayores para los varones en todos los niveles. Las variables referidas a la calificación laboral también tienen los signos esperados, y son mayores para las mujeres en las categorías "Técnico" y "Profesional". La antigüedad en el empleo es también una variable relevante, principalmente en el caso de las mujeres.

De la comparación de los resultados cuando incluimos en la muestra sólo a los trabajadores obreros o empleados, se observa un incremento en la brecha de ingresos a favor de los varones. Paralelamente se observa un aumento de la participación de los coeficientes y una disminución de las dotaciones en este resultado, lo que puede traducirse como un aumento de la situación de discriminación en contra de la mujer.

Por lo tanto, se concluye que en el mercado laboral argentino se penaliza la condición de ser mujer en la obtención de un ingreso. Este aspecto se observa tanto en la segregación ocupacional como con la discriminación de ingresos, fenómenos que desvalorizan el aporte de las mujeres al quehacer económico y social.

Los resultados del presente artículo sugieren el desarrollo de una política laboral que reduzca efectivamente la brecha entre el salario ofrecido y el salario de reserva, con el objeto de aumentar la probabilidad de participación laboral de la mujer. De cierta manera, tal como indican 
Flores y Jasso (2004) la existencia de mujeres fuera del mercado laboral se explicaría por la presencia de ciertas características no observadas que presionan hacia arriba el salario de reserva, incrementando la probabilidad de decidir no entrar en el mercado de trabajo. La implementación de políticas que busquen incrementar el salario ofrecido a la mujer permitiría reducir esa brecha.

Si bien la República Argentina cuenta desde el año 2009 con una ley de igualdad de género ${ }^{12}$ ampliamente debatida y ejemplar por la cobertura que otorga al problema (aunque muy atacada por algunas organizaciones feministas en algunos artículos específicos), la misma no se encuentra totalmente reglamentada. En esta norma se otorga una amplia gama de derechos a la mujer en el ámbito laboral que lograrían poner un claro límite a los resultados observados en esta investigación, aunque la conquista sustancial de los mismos, más allá de una mera formalidad legal, implique la necesidad de múltiples políticas socio-económicas paralelas, e incluso previas. En tal sentido resulta de suma importancia aumentar la visibilidad de la mujer el mundo del trabajo para hacer frente a numerosos prejuicios que limitan su participación. Además, teniendo en cuenta la importancia observada del capital humano en la determinación del ingreso, sería aconsejable trabajar sobre las políticas educativas y de capacitación a los fines de resaltar la utilidad en el desempeño laboral de aquellas cualidades típicamente asociadas al lado femenino del ser.

Por último, y teniendo en cuenta que la literatura ha dado mucho énfasis al análisis microeconómico de las brechas salariales por género, basados en estudios de corte transversal sería interesante extender el análisis a series de tiempo para establecer el efecto probable de los resultados macroeconómicos.

\section{Bibliografía}

Aigner, D. J., y Cain, G. G. (1977). Statistical Theories of Discrimination in Labor Markets. Industrial and Labor Relations Review, 30(2), 175-187.

\footnotetext{
12 Ley Nacional Nro. 26.485 de protección integral para prevenir, sancionar y erradicar la violencia contra las mujeres en los ámbitos en que desarrollen sus actividades interpersonales. Consultar en: http://www.infoleg.gov.ar/infolegInternet/anexos/150000-154999/152155/norma.htm
} 
Altonji, J. G., y Blank, R. (1999). Race and gender in the labor market. Handbook, 3143-3259.

Atal, J. P., Ñopo, H., y Winder, N. (2009). New Century, Old Disparities: Gender and Ethnic Wage Gaps in Latin America. Research Department Publications from Inter-American Development Bank.

Barraza Narváez, N. M. (2010). Discriminación salarial y segregación laboral por género en las áreas metropolitanas de Barranquilla, Cartagena y Montería. Serio de Documentos IEEC(31).

Becker, G. S. (1957). The Economics of Discrimination. Chicago: Chicago University Press.

Becker, G. S. (1975). Human Capital: A Theoretical and Empirical Analysis, with Special Reference to Education. Cambridge: NBER Books.

Bergmann, B. R. (1989). Does the market for women's labor need fixing? The Journal of Economic Perspectives, 43-60.

Cain, S. (1986). The Economic Analysis of Labor Market. Handbook of Labor Economics, 1(13).

Carranza, J. P., y Peralta, P. I. (2012). Empleo y género: análisis de las preferencias de los empleadores como determinantes del acceso al empleo. El caso de la ciudad de Córdoba, Argentina. Nomadías.

Carrasco, S. E. (2004). Unidad de Análisis de Políticas Sociales y Económicas. Análisis económico UDAPE, 19.

Esparta Polanco, D. (2012). Discriminación salarial por género según trabajadores asalariados e independientes en el Perú. Horizonte Económico(2), 81-98.

Esquivel, V. (2007). Género y diferenciales de salarios en la Argentina. En M. Novick, y H. Palomino, Estructura productiva y empleo. Un enfoque transversal. (págs. 363-392). Buenos Aires: Ministerio de Trabajo, Empleo y Seguridad Social.

Flores, G., y Jasso, I. (2004). La brecha salarial en México frente al capital humano, discriminación y selección muestral. Gaceta de Economía, 8(15). 
Fortin, N. M. (2005). Labour Market outcome of Women across OECD Countries. Oxford Review of Economic Policy, 21(3), 416-438.

Fortin, N. M. (2007). Gender Role Attitudes and Women's Labor Market Participation: The Persistent Appeal of Housewifery. Meeting of the Population Association of America.

Fuentes, J., Palma, A., y Montero, R. (2005). Discriminación salarial por género en Chile: Una mirada global. Estudios de Economía, 32(2), 133-157.

Goldin, C. (2002). A Pollution Theory of Discrimination: Male and Female Differences in Occupations and Earnings. NBER Working Paper no. 8985, $1-46$.

Heckman, J. (1979). Sample bias as a specification error. Econometrica(47).

Jann, B. (2008). A Stata implementation of the Blinder-Oaxaca decomposition. The Stata Journal, 8(4), 453-479.

Kunze, A. (2000). The Determination of Wages and the Gender Wage Gap: A Survey. IZA Discussion Paper(193).

Lazear, E., y Moore, R. (1984). Incentives, Productivity and Labor Contracts. Quarterly Journal of Economics (99), 275-295.

Macpherson, D., y Hirsch, B. (1995). Wages and gender composition: why do women's jobs pay less? Journal of Labor Economics, 13(3).

Mincer, J. (1974). Schooling, Experience and Earnings. Washington D.C.: Columbia University Press.

Ministerio de Trabajo, Empleo y Seguridad Social de la República Argentina. (2006). Trabajo, ocupación y empleo. Especialización productiva, tramas y negociación colectiva.

Neuman, S., y Oaxaca, R. (2004). Wage differentials in the 1990s in israel: endowments, discrimination and selectivity. Londres: Centre for Economic Policy Research.

Oaxaca, R. (1973). Male-female wage differentials in urban labor market. International Economic Review, 14(3). 
OIT. (2011). Trabajo. Ginebra: Oficina Internacional del Trabajo.

Palomino, H., y Dalle, P. (2012). El impacto de los cambios ocupacionales en la estructura social de la Argentina: 2003-2011. Revista de Trabajo, 10(8), 205-223.

Paz, J. (2000). En cuanto y por qué difieren las remuneraciones entre sexos en Argentina. Anales de la AAEP.

Perona, E. (2012). ¿Qué es la Economía Feminista? En E. Perona (Ed.), Economía Feminista: Ensayos sobre el papel de la mujer en la Economía, la Educación y el Desarrollo (págs. 13-34). Córdoba, Argentina: Asociación Cooperadora de la Facultad de Ciencias Económicas de la Universidad Nacional de Córdoba.

Psacharopoulos, G., y Tzannatos, Z. (1991). Female labor force participation and education. En Essays on Poverty, Equity and Growth. Oxford: Pergam on Press for the World Bank.

Zúñiga, G., y Orlando, M. B. (2001). Trabajo femenino y brecha de ingresos por género en Venezuela. Papeles de Población, 27, 63-98. 


\section{Anexo. Descripción de variables.}

\begin{tabular}{|c|c|c|c|c|c|c|c|}
\hline Variable & Descripción & $\begin{array}{c}\text { Media } \\
\text { Total }\end{array}$ & $\begin{array}{l}\text { Media } \\
\text { Mujer }\end{array}$ & $\begin{array}{l}\text { Media } \\
\text { Varón }\end{array}$ & $\begin{array}{l}\text { Std. } \\
\text { Err. }\end{array}$ & \multicolumn{2}{|c|}{$\begin{array}{l}\text { [95\% Conf. } \\
\text { Interval] }\end{array}$} \\
\hline LogYhora & Logaritmo del ingreso neto por hora & 2,802 & 2,794 & 2,808 & 0,005 & 2,792 & 2,812 \\
\hline FEM_Vertical & $\begin{array}{l}\text { Proporción de mujeres (sobre el total de personas con } \\
\text { ingresos }>0 \text { ) en cada jerarquía ocupacional }\end{array}$ & 0,424 & 0,431 & 0,419 & 0,000 & 0,423 & 0,425 \\
\hline FEM_Horizontal & $\begin{array}{l}\text { Proporción de mujeres (sobre el total de personas con } \\
\text { ingresos }>0 \text { ) en cada sector de actividad económica }\end{array}$ & 0,426 & 0,609 & 0,292 & 0,002 & 0,422 & 0,429 \\
\hline Edad & Edad del individuo & 39,571 & 39,828 & 39,386 & 0,088 & 39,398 & 39,744 \\
\hline Edad2 & Edad del individuo al Cuadrado & $\begin{array}{r}1736,88 \\
8\end{array}$ & $\begin{array}{r}1745,05 \\
6\end{array}$ & $\begin{array}{r}1730,96 \\
3\end{array}$ & 7,563 & $\begin{array}{r}1722,06 \\
5\end{array}$ & $\begin{array}{r}1751,71 \\
1\end{array}$ \\
\hline Hs trabajadas por semana & Horas trabajadas por semana & 40,338 & 33,843 & 45,050 & 0,209 & 39,928 & 40,749 \\
\hline Pareja & Dummy, 1 si tiene pareja & 0,599 & 0,516 & 0,659 & 0,003 & 0,592 & 0,605 \\
\hline Trabajo Formal & $\begin{array}{l}\text { Dummy, } 1 \text { si tiene vacaciones pagas, cobra aguinaldo, } \\
\text { tiene obra social y le realizan descuento jubilatorio }\end{array}$ & 0,501 & 0,504 & 0,500 & 0,003 & 0,495 & 0,508 \\
\hline Calificación $=$ Profesional & Dummy, 1 si la calificación laboral es Profesional & 0,086 & 0,093 & 0,081 & 0,002 & 0,082 & 0,090 \\
\hline Calificación $=$ Técnico & Dummy, 1 si la calificación laboral es Técnico & 0,183 & 0,221 & 0,155 & 0,003 & 0,178 & 0,188 \\
\hline Calificación $=$ Operario & Dummy, 1 si la calificación laboral es Operativo & 0,501 & 0,372 & 0,595 & 0,003 & 0,494 & 0,508 \\
\hline No Calificado & Dummy, 1 si la no tiene calificación laboral & 0,225 & 0,309 & 0,164 & 0,003 & 0,220 & 0,231 \\
\hline Subocupado demandante & $\begin{array}{l}\text { Dummy, } 1 \text { si es subocupado y demanda más horas para } \\
\text { trabajar }\end{array}$ & 0,057 & 0,074 & 0,045 & 0,002 & 0,054 & 0,060 \\
\hline Subocupado NO demandante & $\begin{array}{l}\text { Dummy, } 1 \text { si es subocupado y no demanda más horas } \\
\text { para trabajar }\end{array}$ & 0,018 & 0,027 & 0,012 & 0,001 & 0,016 & 0,020 \\
\hline Ocupado pleno & Dummy, 1 si es ocupado pleno & 0,558 & 0,674 & 0,475 & 0,003 & 0,552 & 0,565 \\
\hline Sobreocupado & Dummy, 1 si es sobreocupado & 0,366 & 0,225 & 0,468 & 0,003 & 0,359 & 0,372 \\
\hline Antigüedad menor 1 año & $\begin{array}{l}\text { Dummy, } 1 \text { si la antigüedad en el empleo es menor a un } \\
\text { año }\end{array}$ & 0,137 & 0,113 & 0,154 & 0,002 & 0,133 & 0,142 \\
\hline Antigüedad 1 a 5 años & $\begin{array}{l}\text { Dummy, } 1 \text { si la antigüedad en el empleo es entre } 1 \text { y } 5 \\
\text { años }\end{array}$ & 0,305 & 0,288 & 0,318 & 0,003 & 0,299 & 0,312 \\
\hline Antigüedad mayor a 5 años & $\begin{array}{l}\text { Dummy, } 1 \text { si la antigüedad en el empleo es mayor a } 5 \\
\text { años }\end{array}$ & 0,479 & 0,418 & 0,523 & 0,003 & 0,472 & 0,485 \\
\hline Jerarquía = Dirección & Dummy, 1 si la jerarquía ocupacional es Dirección & 0,055 & 0,039 & 0,067 & 0,002 & 0,052 & 0,059 \\
\hline Jerarquía = Cuentapropia & Dummy, 1 si la jerarquía ocupacional es Cuenta Propia & 0,184 & 0,154 & 0,205 & 0,003 & 0,179 & 0,189 \\
\hline Jerarquía $=$ Jefe & Dummy, 1 si la jerarquía ocupacional es Jefe & 0,020 & 0,014 & 0,025 & 0,001 & 0,018 & 0,022 \\
\hline Jerarquía $=$ Asalariado & Dummy, 1 si la jerarquía ocupacional es Asalariado & 0,736 & 0,788 & 0,698 & 0,003 & 0,730 & 0,742 \\
\hline Sin Instrucción & $\begin{array}{l}\text { Dummy, } 1 \text { si el nivel educativo es sin instrucción de } \\
\text { ningún tipo }\end{array}$ & 0,046 & 0,035 & 0,053 & 0,001 & 0,043 & 0,049 \\
\hline Primaria completa & Dummy, 1 si el nivel educativo es primaria completa & 0,177 & 0,142 & 0,202 & 0,003 & 0,172 & 0,182 \\
\hline Secundaria completa & Dummy, 1 si el nivel educativo es secundaria completa & 0,268 & 0,251 & 0,281 & 0,003 & 0,263 & 0,274 \\
\hline Secundaria incompleta & $\begin{array}{l}\text { Dummy, } 1 \text { si el nivel educativo es secundaria } \\
\text { incompleta }\end{array}$ & 0,170 & 0,131 & 0,198 & 0,003 & 0,165 & 0,175 \\
\hline Universitario completo & $\begin{array}{l}\text { Dummy, } 1 \text { si el nivel educativo es universitaria } \\
\text { completa }\end{array}$ & 0,208 & 0,292 & 0,148 & 0,003 & 0,203 & 0,214 \\
\hline Universitario incompleto & $\begin{array}{l}\text { Dummy, } 1 \text { si el nivel educativo es universitaria } \\
\text { incompleta }\end{array}$ & 0,131 & 0,148 & 0,118 & 0,002 & 0,126 & 0,135 \\
\hline Región = Patagonia & Dummy, 1 si la región es Patagonia & 0,149 & 0,148 & 0,149 & 0,002 & 0,144 & 0,153 \\
\hline Región = GBA & Dummy, 1 si la región es Gran Buenos Aires & 0,151 & 0,155 & 0,147 & 0,002 & 0,146 & 0,155 \\
\hline Región $=$ NOA & Dummy, 1 si la región es Noroeste & 0,188 & 0,191 & 0,186 & 0,003 & 0,183 & 0,193 \\
\hline Región = NEA & Dummy, 1 si la región es Noreste & 0,110 & 0,110 & 0,110 & 0,002 & 0,105 & 0,114 \\
\hline Región = Cuyo & Dummy, 1 si la región es Cuyo & 0,095 & 0,092 & 0,097 & 0,002 & 0,091 & 0,099 \\
\hline Región = Pampeana & Dummy, 1 si la región es Pampeana & 0,308 & 0,304 & 0,311 & 0,003 & 0,302 & 0,314 \\
\hline Menores en el hogar & Dummy, 1 si hay menores de 10 años en el hogar & 0,639 & 0,592 & 0,672 & 0,006 & 0,626 & 0,651 \\
\hline Miembros del hogar & Cantidad de miembros en el hogar & 3,993 & 3,851 & 4,096 & 0,014 & 3,966 & 4,021 \\
\hline Inquilino & Dummy, 1 si paga alquiler & 0,197 & 0,206 & 0,191 & 0,003 & 0,192 & 0,202 \\
\hline
\end{tabular}


Brecha de ingresos por género en Argentina

\begin{tabular}{|c|c|c|c|c|c|c|c|}
\hline ¿Vive del trabajo? & Dummy, 1 si declara vivir del trabajo & 0,996 & 0,994 & 0,997 & 0,001 & 0,994 & 0,997 \\
\hline Jefe de hogar & Dummy, 1 si declara ser jefe de hogar & 0,508 & 0,332 & 0,636 & 0,003 & 0,501 & 0,515 \\
\hline Ingreso familiar & $\begin{array}{l}\text { Ingreso total famiiar menos el ingreso de la ocupación } \\
\text { principal }\end{array}$ & $\begin{array}{r}4256,92 \\
7\end{array}$ & $\begin{array}{r}4809,64 \\
1\end{array}$ & $\begin{array}{r}3855,96 \\
4\end{array}$ & $\begin{array}{r}29,59 \\
0\end{array}$ & $\begin{array}{r}4198,92 \\
8\end{array}$ & $\begin{array}{r}4314,92 \\
6\end{array}$ \\
\hline Ingreso NO laboral & Ingreso no laboral del individuo & 182,619 & 238,746 & 141,903 & 5,679 & 171,488 & 193,751 \\
\hline Años de escolaridad & Años de escolaridad aprobados & 11,387 & 12,054 & 10,903 & 0,024 & 11,339 & 11,435 \\
\hline
\end{tabular}

Fuente: Elaboración propia con datos de la EPH para el segundo trimestre de 2012. 